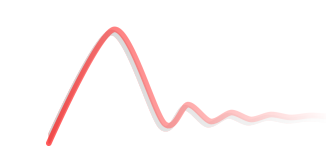
Dynare Working Papers Series
https://www.dynare.org/wp/

\title{
The Vietnamese business cycle in an estimated small open economy New Keynesian DSGE model
}

\author{
Phuong Van Nguyen
}

Working Paper no. 56

February 2020

\author{
CE P R E M A P \\ CENTRE POUR LA RECHERCHE ECONOMIQUE ET SES APPLICATIONS \\ 48, boulevard Jourdan - 75014 Paris - France \\ https: //www. cepremap.fr
}




\title{
The Vietnamese business cycle in an estimated small open economy New Keynesian DSGE model*
}

\author{
Phuong Van Nguyen ${ }^{\dagger}$
}

\begin{abstract}
The primary purpose of this paper is to investigate the sources of the business cycle fluctuations in Vietnam. To this end, we develop a small open economy New Keynesian Dynamic Stochastic General Equilibrium (SOE-NK-DSGE) model. Accordingly, this model includes various features, such as habit consumption, staggered price, price indexation, incomplete exchange-rate pass-through, the failures of the law of one price and the uncovered interest rate parity. It is then estimated by using the Bayesian technique and Vietnamese data 1999Q1 - 2017Q1. Based on the estimated model, this paper analyzes the sources of the business cycle fluctuations in this emerging economy. Indeed, this research paper is the first attempt on developing and estimating the SOE-NK-DSGE model with the Bayesian technique for Vietnam.
\end{abstract}

JEL classification: E12, E31, E32, E47, E52, F41, F43.

Keywords: International macroeconomics; the international spillover; the Vietnamese economy; the New Keynesian DSGE model; the Bayesian estimation.

${ }^{*}$ I want to thank Maik Wolters, Hans-Werner Wohltmann, and Pierpaolo Benigno for their valuable suggestions and comments during my doctoral studies at the University of Kiel, and the Advanced Study Program at the Kiel Institute for the World Economy, Germany. The opinions, findings, conclusions, recommedations expressed herein are my own and do not reflect the views of people in the PhD Quantitative Economic Program at the University of Kiel.

${ }^{\dagger}$ Address correspondence to: Phuong V. Nguyen, R.113, Leibnizstra 3, 24118 Kiel, Germany. Email address: phuong.nguyen@economics.uni-kiel.de 


\section{Introduction}

The primary purpose of this research paper is to address the question of what sources drive the business cycle fluctuations in Vietnam, in particular over the period of 1999Q1 to 2017Q1? To this end, we develop and estimate a small open economy New Keynesian Dynamic Stochastic General Equilibrium (SOE-NK-DSGE) model. This question is particularly interesting because Vietnam has witnessed large fluctuations in the business cycle for over 30 years. For example, Figure 1 presents that after launching the Revolution in 1986, known as Doi Moi, the Vietnamese GDP growth has been rocketing and reaches a peak of $9.54 \%$ in 1995. However, due to the Asian financial crisis in 1997, this economy experiences a great fall. Afterward, Vietnam maintains a stable and high growth rate of output at approximately $6.52 \%$ per year on average. Moreover, based on the World Bank report, this growth rate is always notably higher than the world. Because of the 2008 financial global crisis, there is a fall in output growth. However, the Vietnamese economy has quickly recovered and caught up with the output growth of China since 2015.

Figure 1: The annual output growth of Vietnam and its trend, 1985-2017

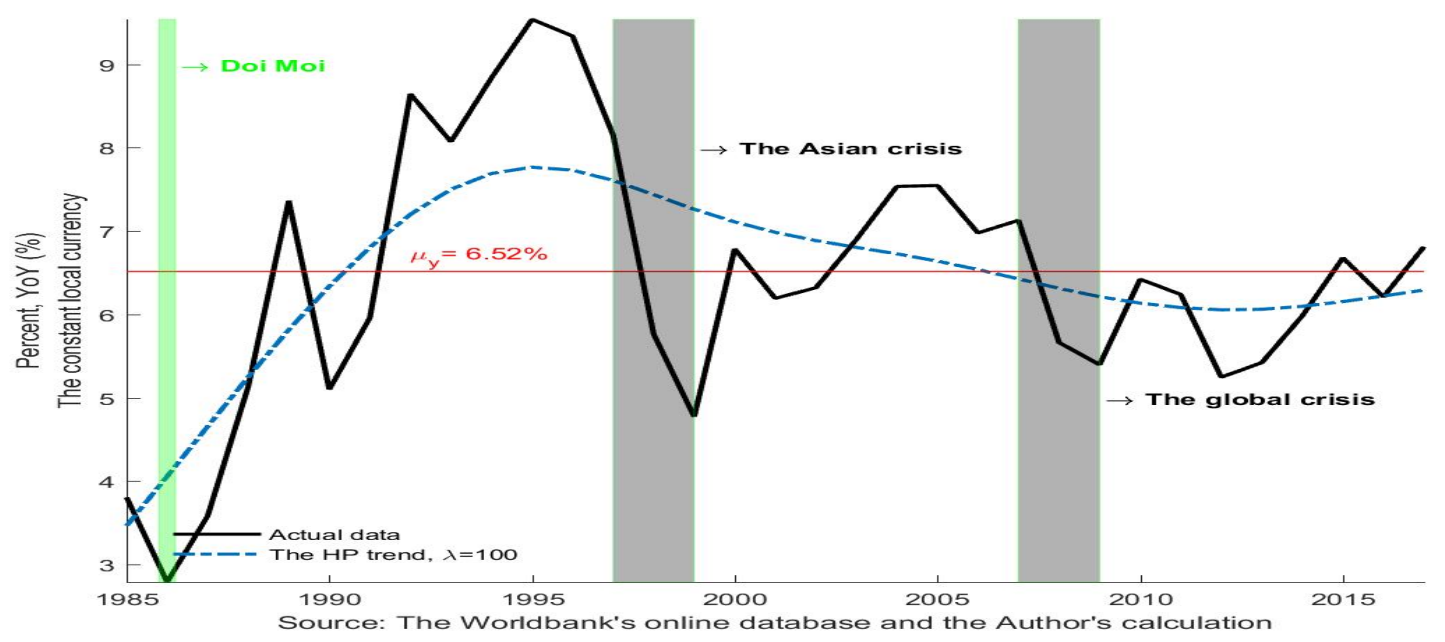

On the other hand, the New Keynesian Dynamic Stochastic General Equilibrium (NKDSGE) model has been widely used for macroeconomic policy analysis. Thus, over the last decade, an increasing number of attempts have developed and estimated both Real Business Cycle (RBC) and DSGE models for other developing and emerging countries (Oviedo and Yue (2009). García-Cicco et al. (2010), Elisa and Padilla (2011), Mendoza (2010), García-Cicco et al. (2010), Boz et al. (2011), Mendoza and Yue (2012), etc). However, the literature on estimating a DSGE model for Vietnam is still limited. Thus, this paper is the first attempt of developing and estimating the SOE-NK-DSGE model with a wide range of important features for Vietnam.

One of the most striking features of the Vietnamese economy is that this emerging country strongly depends on international trade. International trade and financial linkage are particularly essential to this country. Based on the World Bank Database, for example, 
the Vietnamese degree of opennes: $\mathrm{I}^{1}$ (red line) has been significantly increasing since 2000 (see Figure 2). Thus, Vietnam became one of the most open economies in the world. As an example, this Figure presents Singapore as the most open economy in the ASEAN region, followed by Vietnam. Moreover, in 2017 this indicator reaches a considerably impressive level of $200 \%$, which is six times and four times as much as in China and the world, respectively. Thus, a structural model including the foreign sector, such as the SOE-NK-DSGE model, is important to explain the business cycle fluctuation in this country.

Figure 2: The annual openness of some selected emerging Asian nations, 1986-2017

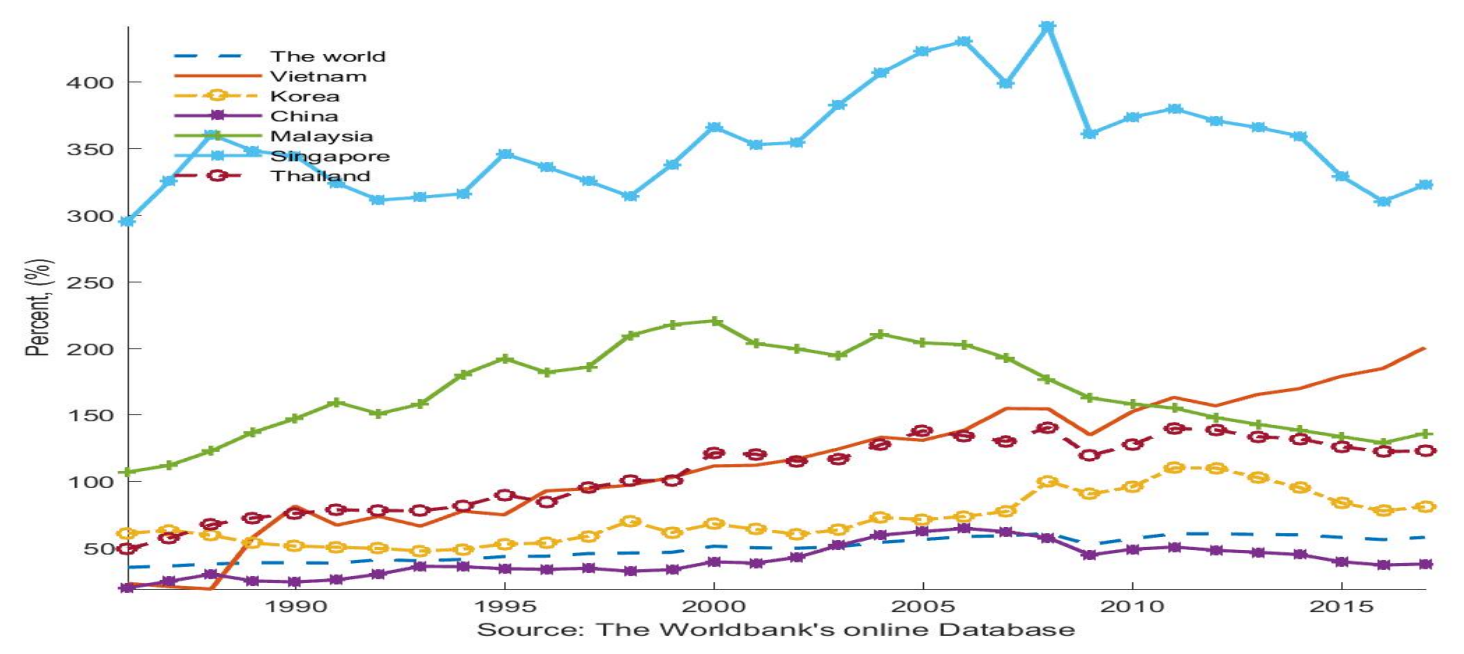

To this end, we develop a small open economy New Keynesian Dynamic Stochastic General Equilibrium (SOE-NK-DSGE) model. In particular, the specification of this model closely follows the influential studies by Gali and Monacelli (2005), Monacelli (2005), and Justiniano and Preston (2010b) on the small open economy. Thus, our model includes various important features, such as habit formation, price stickiness, price indexation, the failure of the Uncovered Interest Rate Parity, the Law of One Price gap, and incomplete exchange-rate pass-through. However, the most striking difference between the SOE-NK-DSGE model in this paper and those in the three above studies is as follows. We model the foreign economy as a closed economy DSGE model rather than a reduced VAR one.

Empirically, our model estimation closely follows the vast literature on estimating the NK-DSGE model with the Bayesian technique (Smets and Wouters (2003, 2007), An and Schorfheide (2007), Adolfson et al. (2007), Negro and Schorfheide (2008), etc). Thus, to the best of our knowledge, this project is the first attempt of developing and estimating a SOE-NK-DSGE model for Vietnam.

The estimated SOE-NK-DSGE model with the Bayesian technique fits data on the Vietnamese and foreign economies relatively well. As an example, in most of the vari-

\footnotetext{
${ }^{1}$ The degree of openness is measured as the ratio of import and export to GDP.
} 
ables, the fitted value insignificantly differs from its actual data, in particular, domestic interest rate and CPI inflation. Based on this estimated model, we find that the inflation dynamic in Vietnam is purely forward-looking behavior. It implies that expected inflation strongly influences the fluctuations in current inflation. On the other hand, no structural shock permanently affects the Vietnamese economy. Indeed, after the shock, the observed macroeconomic variables quickly go back to their steady-state level, except for domestic CPI inflation and interest rate.

We also find that there is a stronger response in domestic output growth than domestic CPI inflation to the monetary tightening. Thus, during the period of anti-inflation, the SBV should implement a contractionary monetary policy with caution. Furthermore, the short-run incomplete exchange rate pass-through (ERPT) of around $27 \%$ after three months implies a high and rapid ERPT in Vietnam. Therefore, the SBV's domestic currency devaluation policy, which is to promote exports, should be conducted with caution. Because of the 2008-global financial crisis, for example, this central bank devaluated the DONG currency relative to the US-Dollar. As a result, this policy caused the two-digit inflation in 2008 and 2011.

As one of the most open economies in the world, the fluctuations in interest rate and the real and nominal exchange rates in Vietnam are strongly influenced by the external-sector disturbances. However, the shock to the term of trade accounts for a mild percentage in explaining the fluctuations in the output growth. This finding is identical to a recent striking study by Schmitt-Grohé and Uribe (2018) on the role of the term-of-trade shock to the developing and emerging markets. On the other hand, the domestic disturbances, including stationary productivity and preference shocks account for a sizeable proportion in explaining the changes in domestic CPI inflation and the term of trade.

Last but not least, in most episodes over the whole sample period 1999Q1-2017Q1, the variations in the Vietnamese output growth rate were highly associated with the demandside disturbance (preference and risk premium shocks). Meanwhile, the fluctuations in the CPI inflation were mainly influenced by monetary policy shocks and the demand-side disturbance (import cost-push shock).

The rest of this paper is organized as follows. Section 2 introduces the literature on estimating the Real Business Cycle and DSGE models for developing and emerging countries, including Vietnam. Section 3 presents the underlying theoretical SOE-NKDSGE model. Section 4 shows model solution and data. Section 5 gives a detailed discussion about the estimation strategy and estimation procedure. Section 6 analyzes the sources of the business cycle fluctuations in Vietnam. Section 7 provides some conclusions.

\section{The related Literature and Contributions}

\subsection{The Literature on the Emerging Market Universe}

The sources of movements in the business cycle in the emerging countries are one of the growing interests over the last decade. Accordingly, both the real business cycle 
(RBC) and NK-DSGE models are widely applied to address this issue as follows.

First, in regard to using the $\mathrm{RBC}$ model, the role of interest rate to the variations in the aggregate activities in seven emerging markets, including Argentina, Brazil, Ecuador, Mexico, Peru, Philippines, and South Africa, are examined in the studies by Neumeyer and Perri (2005), Uribe and Yue (2006), Oviedo and Yue (2009). Meanwhile, the impacts of trend growth shock on the business cycle movements in the emerging countries are shown in studies by Aguiar and Gopinath (2007), García-Cicco et al. (2010), Boz et al. (2011). Furthermore, the contributions of both the total-factor productivity (TFP) and real interest rate to the business cycle movements are examined by Benjamin and Meza (2009), Elisa and Padilla (2011). Additionally, financial frictions are confirmed to be important in explaining the business cycle variations in the emerging economies (see García-Cicco et al. (2010), Mendoza (2010), Mendoza and Yue (2012)). On the other hand, the studies by Benjamin and Meza (2009), Kehoe and Ruhl (2009), and Boz et al. (2015) highlight the important role of labor market frictions in examining the South Korean and Mexican aggregate activities.

Second, regarding the NK-DSGE model, there are various papers estimating this model for policy analysis in the developing and emerging economies (Liu and Zhang $(2010), \mathrm{Gu}$

et al. (2014), Dai et al. (2015) for China; Elekdag et al. (2005), Choi and Hur (2015) for Korea; Sahminan et al. (2017), Gu et al. (2014) for Indonesia; Ramayandi (2011) for 4 ASEAN countries such as Malaysia, Thailand, Indonesia and Philippines; Saxegaard et al. (2010), Gabriel et al. (2016) for India; Silveira (2008), Palma and Portugal (2014) for Brazil, Castillo et al. (2013) for Peru, Medina and Soto (2007) for Chile and Steinbach et al. (2009) for the South Africa).

\subsection{The literature on Vietnam and Contributions}

As mentioned above, over the last decade, an increasing number of attempts developed and estimated the DSGE model for other developing and emerging countries. However, the literature on estimating a DSGE model for Vietnam is still limited. On the other hand, several attempts investigated the Vietnamese business cycle fluctuations by using either non- or structural models as follows. For example, Le (2014) compared the variations in the business cycle between Vietnam and Indonesia in the context of a structural VAR model. Pham (2018) investigated the role of government expenditure in the lens of a closed-economy real business cycle model. Sala et al. (2019) examined the role of permanent productivity shock to five real aggregate variables in Vietnam. Accordingly, this shock delivered an insignificant contribution. However, it is worth noting that both Pham (2018) and Sala et al. (2019) used an estimated real business cycle model. Hence, the role of monetary policy and other nominal frictions, such as price rigidity and incomplete exchange-rate pass-through, were not included in these two research papers. Khieu (2014) evaluated the role of the Vietnamese monetary policy in an estimated threeequation closed economy NK-DSGE model. Indeed, this author used a model, which was developed by Ireland (2004). Huynh et al. (2017) used a calibrated DSGE model with the 
banking sector to investigate how policies stabilize the Vietnamese economy. However, both Khieu (2014) and Huynh et al. (2017) were limited to the aspect of a closed-economy. Hence, these two studies could not reveal the essential effects of the international spillovers on the Vietnamese economy. Given that Vietnam has one of the most open economies in the world, the presence of the foreign sector in the underlying model is especially relevant to explaining the business cycle fluctuations in this emerging country.

The research paper by Dizioli and Schmittmann (2015) is interesting since the foreign sector was included in this study. In particular, these authors described the Vietnamese economy in the framework of the Forecasting and Policy Analysis System (FPAS) model. Indeed, this model was developed by Berg and Laxton (2006a), Berg and Laxton (2006b), and used at the IMF. Accordingly, the FPAS model includes four fundamental equations: aggregate demand curve, price dynamic, uncovered interest rate, and monetary policy rule. However, Dizioli and Schmittmann (2015) aimed to seek the optimal monetary policy rather than the explanations for the business cycle fluctuations. For example, they argued that the optimal rule in Vietnam places more significant weight on output stabilization as the intermediate target to achieve inflation stability, while allowing greater exchange rate flexibility. Therefore, the source of the business cycle fluctuations in this country and the effects of international spillovers were never discussed. Indeed, there was no discussion about the forecast error variance decomposition and historical decomposition techniques in this research.

This underlying study has two main contributions to the current literature. First, it is the first attempt of developing and estimating the SOE-NK-DSGE model with a wide range of important features for Vietnam. Second, it contributes to the growing interests of explanation for the sources of business cycle fluctuations in emerging markets.

\section{The theoretical model}

\subsection{An Overview of the theoretical model}

It is worth noting that the small-sized model in this paper has three main agents in the domestic economy: household, firm, and central bank. Thus, there is no government sector. Furthermore, the quarterly data on investment is typically not available in the developing and emerging markets. Therefore, we do not incorporate the variable of investment into the underlying theoretical model.

Figure 3 below presents the agent's interaction. For example, in supply-side, the domestic firm produces its goods by combining stationary technology and the labor supply of the household. It also exports its goods to the foreign economy. Conversely, the importing firm does not produce its goods. Instead, it imports goods from the foreign economy and sells them to the domestic household. The presence of this importing firm enables us to derive the law of one price gap since the Law Of One Price (LOOP) fails to hold. Furthermore, the model includes nominal friction such as the sticky price in the importing firm. Thus, the exchange-rate pass-through is incomplete. On the other hand, 
in demand-side, the assumption of the household's holding of domestic and foreign bonds enables us to derive the Uncovered Interest Rate Parity, well known as the UIP. However, the UIP never holds in Vietnam because of the imperfect capital mobility. To coincide with this issue, we introduce the risk premium function. Finally, we close the model by introducing the monetary policy. Indeed, the role of the central bank is described via the Taylor rule including the exchange rate.

Figure 3: Graphical illustration of a small open-economy New Keynesian DSGE model

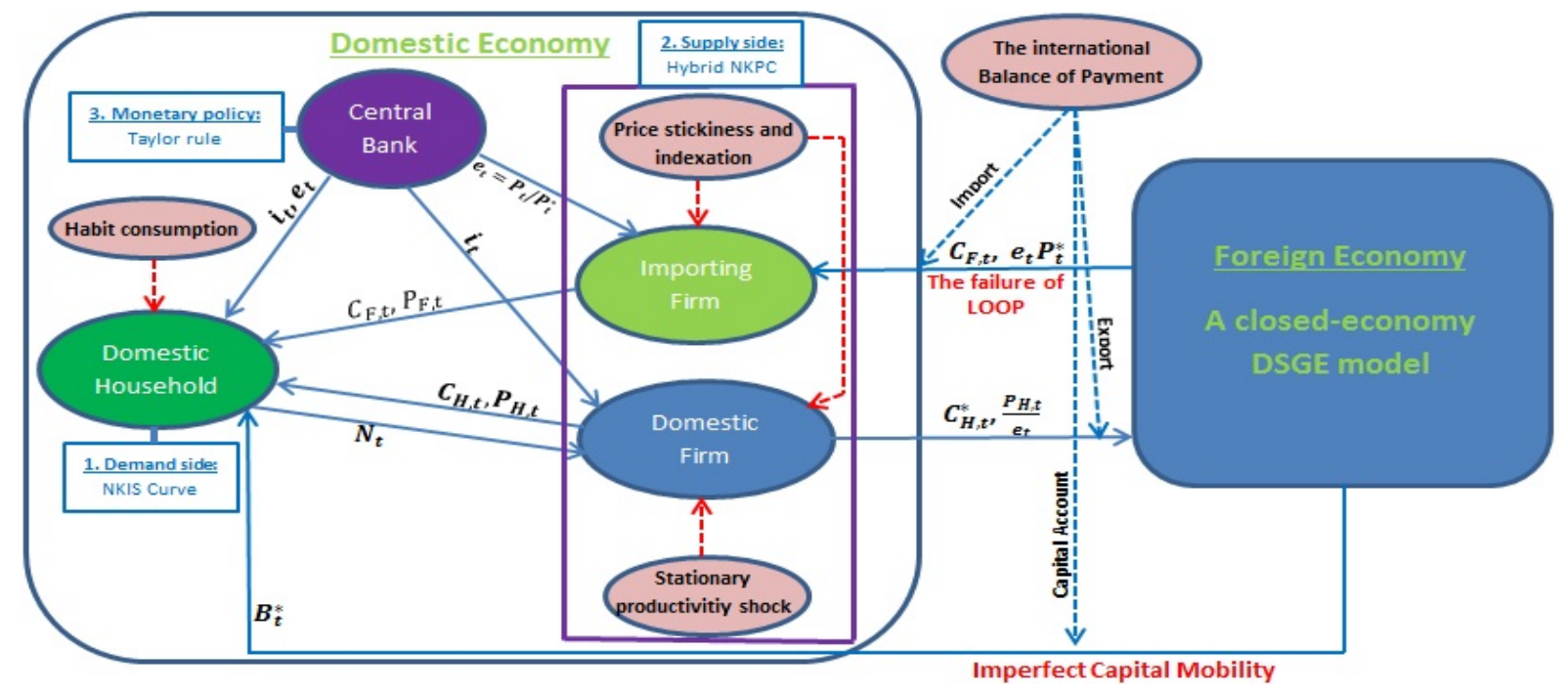

The following sections shortly present several striking features of the theoretical model of SOE-NK-DSGE. Meanwhile, the detailed specification and solution for this conceptual model can be found in the over-60-page mathematical appendix.

\subsection{Household}

Each household maximizes its following utility.

$$
E_{0} \sum_{t=0}^{\infty} \beta^{t} \tilde{\varepsilon}_{g, t}\left[\frac{\left(C_{t}-h C_{t-1}\right)^{1-\sigma}}{1-\sigma}-\frac{N_{t}^{1+\varphi}}{1+\varphi}\right]
$$

where $\beta$ and $h$ are a discount factor and habit formation, respectively. The variable $N_{t}$ is the household's worked labor. Two positive parameters $(\sigma, \varphi)$ are the inverse elasticity of intertemporal substitution and labor disutility, respectively. $\tilde{\varepsilon}_{g, t}$ represents a preference shock. Specifically, $C_{t}$ is the aggregate consumption:

$$
C_{t}=\left[(1-\alpha)^{\frac{1}{\eta}} C_{H, t}^{\frac{\eta-1}{\eta}}+\alpha^{\frac{1}{\eta}} C_{F, t}^{\frac{\eta-1}{\eta}}\right]^{\frac{\eta}{\eta-1}}
$$

where parameter $\alpha$ is the share of imported goods in the domestic aggregate consumption. Parameter, $\eta$, indicates the elasticity of substitution between domestic goods $C_{H, t}$ and imported goods $C_{F, t}$ in which they are the Dixit-Stiglitz aggregate type such as below. 


$$
C_{H, t}=\left[\int_{0}^{1} C_{H, t}(i)^{\frac{\varepsilon-1}{\varepsilon}} d i\right]^{\frac{\varepsilon}{\varepsilon-1}} \text { and } C_{F, t}=\left[\int_{0}^{1} C_{F, t}(i)^{\frac{\varepsilon-1}{\varepsilon}} d i\right]^{\frac{\varepsilon}{\varepsilon-1}}
$$

where the parameter $(\varepsilon)$ is the elasticity of substitution between types of differentiated domestic and imported goods.

The procedure for the optimization of each household will take place subject to the following flow budget constraint.

$$
P_{t} C_{t}+D_{t}+e_{t} B_{t}=D_{t-1}\left[1+\tilde{i}_{t-1}\right]+e_{t} B_{t-1}\left[1+\tilde{i}_{t-1}^{*}\right] \phi\left(A_{t}\right)+W_{t} N_{t}+\Pi_{H, t}+\Pi_{F, t}
$$

for all $t>0, D_{t}, B_{t}$ are one-period domestic and foreign bonds, respectively. Domestic and international interest rates are $\tilde{i}_{t}, \tilde{i}_{t}^{*}$. The nominal exchange rate is presented as $e_{t}$ and domestic CPI price is $P_{t}$. The variable $W_{t}$ is wage and $\Pi_{H, t}, \Pi_{F, t}$ represent the dividend from domestic and imported goods firms. Furthermore, the function $\phi\left(A_{t}\right)$ is referred to a debt elastic interest rate premium. It is mainly driven by two important foreign variables: the real value of foreign bond $A_{t}$ and risk premium disturbance $\tilde{\phi}_{t}$ as

$$
\phi\left(A_{t}\right)=\exp \left[-\chi\left(A_{t}+\tilde{\phi}_{t}\right)\right]
$$

It is worth noting that $A_{t}$ denotes the relative value of the real quantity of outstanding foreign bond in term of home currency to steady-state output $\bar{Y}$. It is measured as $A_{t}=$ $\frac{\tilde{e}_{t-1} B_{t-1}}{\bar{Y} P_{t-1}}$. The specification of the risk premium function, $\phi\left(A_{t}\right)$, is identical to SchmittGrohé and Uribe (2003), Adolfson et al. (2007) and the strictly decreasing function in $A_{t}$. The presence of this function in the model causes the foreign debt level in a loglinear approximation to be stationary. For example, Schmitt-Grohé and Uribe (2003) explained "To see why this device induces stationarity, let $p\left(d_{t}\right)$ denote the premium over the world interest rate paid by domestic residents, and $d_{t}$ the stock of foreign debt. Then in the steady-state the Euler equation implies that $\beta[1+r+p(d)]=1$. This expression determines the steady-state net foreign asset position as a function of $r$ and the parameters that define the premium function $p($.$) only."$

Furthermore, the presence of the risk premium function enables us to capture imperfect integration in the international financial market (Schmitt-Grohé and Uribe (2003), Adolfson et al. (2008), Justiniano and Preston (2010b)). Therefore, this specification is especially relevant to Vietnam, where capital mobility is still restricted and the UIP fails to hold.

Each household optimizes its utility by choosing the domestically-made and imported goods, $C_{H, t}(i), C_{F, t}(i)$. It results in the following demand for each good

$$
C_{H, t}(i)=\left[\frac{P_{H, t}(i)}{C_{H, t}}\right]^{-\theta} C_{H, t} \text { and } C_{F, t}(i)=\left[\frac{P_{F, t}(i)}{C_{F, t}}\right]^{-\theta} C_{F, t}
$$

where $P_{H, t}$ and $P_{F, t}$ denote the prices of the domestically-made and imported goods, 
respectively. On the other hand, a household's demand for aggregate domestic and foreign goods are below.

$$
\begin{array}{ll}
\min _{C_{H, t}, C_{F, t}} & P_{t} C_{t}=P_{H, t} C_{H, t}+P_{F, t} C_{F, t} \\
\text { such that } & C_{t}=D_{t}^{\frac{\eta}{\eta-1}} \\
\text { where } & D_{t}=(1-\alpha)^{\frac{1}{\eta}} C_{H, t}^{\frac{\eta-1}{\eta}}+\alpha^{\frac{1}{\eta}} C_{F, t}^{\frac{\eta-1}{\eta}}
\end{array}
$$

The results are given below.

$$
C_{H, t}=(1-\alpha)\left(\frac{P_{H, t}}{P_{t}}\right)^{-\eta} C_{t} \text { and } C_{F, t}=\alpha\left(\frac{P_{F, t}}{P_{t}}\right)^{-\eta} C_{t}
$$

Furthermore, the consumer price index is defined as the combination of these two prices as below.

$$
P_{t}=\left[(1-\alpha) P_{H, t}^{1-\eta}+\alpha P_{F, t}^{1-\eta}\right]^{\frac{1}{1-\eta}}
$$

The combinations of the first-order conditions with respect to consumption $C_{t}$, labor $N_{t}$, and the one-period foreign and domestic bonds $B_{t}$ and $D_{t}$ yield the following standard non-linear equations.

1. The non-linear Euler equation:

$$
\left(C_{t}-h C_{t-1}\right)^{-\sigma}=\beta\left(1+i_{t}\right)\left(\frac{\tilde{\varepsilon}_{g, t+1}}{\tilde{\varepsilon}_{g, t}}\right) \cdot\left(\frac{P_{t}}{P_{t+1}}\right)\left(C_{t+1}-h C_{t}\right)^{-\sigma}
$$

2. The non-linear labor supply:

$$
\frac{N_{t}^{\varphi}}{\left(C_{t}-h C_{t-1}\right)^{-\sigma}}=\frac{W_{t}}{P_{t}}
$$

3. The non-linear UIP:

$$
\left[1+\tilde{i}_{t}\right]=E_{t}\left(\frac{e_{t+1}}{e_{t}}\right)\left[1+\tilde{i}_{t}^{*}\right] \phi\left(A_{t+1}\right)
$$

\subsection{Domestic firms}

Given that there is a continuum of the domestic firm, it produces home goods by combining labor and stationary productivity shock as the production function below.

$$
Y_{H, T}(i)=Z_{t} N_{t}(i)
$$


Where stationary productivity shock follows the AR (1) process

$$
z_{a, t}=\rho_{z} z_{t-1}+\epsilon_{z, t} \text { and } z_{t}=\log \left(Z_{t}\right)
$$

We use this simple production without capital since the quarterly data on the investment is typically not available in the developing and emerging economies. On the other hand, one would investigate both stationary and permanent productivity shocks. The specification of a production function, like in the study by García-Cicco et al. (2010), should be used. However, it is worth noting that the role of technology is no longer dominant in the model with nominal rigidity (see Gali (2002), Smets and Wouters (2003), Ireland (2004), Adolfson et al. (2007)).

The domestic firm produces to fulfill both home and foreign household demand for domestic goods. This demand is given below.

$$
Y_{H, t}(i)=\left[\frac{P_{H, t}(i)}{P_{H, t}}\right]^{-\varepsilon}\left(C_{H, t}+C_{H, t}^{*}\right)
$$

On the other hand, normal rigidity will be introduced as follows. The domestic firm resets its price $\left(P_{H, t}(i)\right)$ according to the Calvo-style setting and indexation $\left(0<\gamma_{H}<1\right)$ to the previous domestic-goods price inflation $\left(\pi_{H, t-1}\right)$. Accordingly, a percentage $\left(1-\theta_{H}\right)$ of the firm can reset their price, whereas the rest $\theta_{H}$ adjust their price based on the following indexation rule

$$
P_{H, t}(i)=P_{H, t-1}(i) \pi_{H, t-1}^{\gamma_{H}} \text { and } \pi_{H, t-1}=\frac{P_{H, t-1}}{P_{H, t-2}}
$$

Since the inflation-targeting policy has not been adopted in Vietnam, the above rule of indexation does not incorporate target inflation. This specification of the above price indexation is identical to the studies of Christiano et al. (2005), Smets and Wouters (2003) . However, other developing and emerging countries have adopted the inflation-targeting policy. The specification of price indexation, such as the study by Adolfson et al. (2007), should be used.

Given the demand for domestic goods (3.3.3), the optimization problem yields the following the domestic firm's real marginal cost.

$$
m c_{H, t}=\frac{W_{t}}{P_{H, t} Z_{t}}
$$

The expression above 3.3 .5 implies that the real marginal cost $\left(m c_{H, t}\right)$ is identical to cross domestic firms and independent of the domestic goods made. On the other hand, because of the Calvo-setting price, the Dixit-Stiglitz aggregate price of the domestic firm will be. 


$$
P_{H, t}=\left[\int_{0}^{1} P_{H, t}^{1-\varepsilon}(i) d i\right]^{\frac{1}{1-\varepsilon}}=\left[\theta_{H}\left(P_{H, t-1} \pi_{H, t-1}^{\delta_{H}}\right)^{1-\varepsilon}+\left(1-\theta_{H}\right)\left(P_{H, t}^{n e w}(i)\right)^{1-\varepsilon}\right]^{\frac{1}{1-\varepsilon}}
$$

Finally, each domestic firm will maximize its following expected present discounted profit subject to the demand curve in 3.3.3.

$$
\max _{P_{H, t}^{\text {new }}(i)} E_{t} \sum_{j=0}^{\infty}\left(\beta \theta_{H}\right)^{j}\left[\left(\frac{P_{H, t+j-1}(i)}{P_{H, t-2}(i)}\right)^{\delta_{H}} P_{H, t}^{\text {new }}(i)-P_{H, t+j} m c_{H, t+j}(i)\right] Y_{H, t+j}(i)
$$

The procedure for the optimization results in the following expression

$$
E_{t} \sum_{j=0}^{\infty}\left(\beta \theta_{H}\right)^{j} Y_{H, t+j}(i)\left[P_{H, t}^{n e w}(i)\left(\frac{P_{H, t+j-1}}{P_{H, t-1}}\right)^{\delta_{H}}-\frac{\varepsilon}{\varepsilon-1} P_{H, t+j} m c_{H, t+j}(i)\right]=0
$$

Taking a log-linear approximation of the above expression will lead to a Hybrid New Keynesian Philip Curve for the domestic firm.

$$
\widehat{\pi}_{H, t}=\frac{\beta}{1+\beta \delta_{H}} \widehat{\pi}_{H, t+1}+\frac{\delta_{H}}{1+\beta \delta_{H}} \widehat{\pi}_{H, t-1}+\frac{\left(1-\theta_{H}\right)\left(1-\beta \theta_{H}\right)}{\theta_{H}\left(1+\beta \delta_{H}\right)} \widehat{m c}_{H, t}
$$

\subsection{Importing firms}

Since the domestic household's consumption packet includes both domestic and foreign goods, the purpose of the importing firm is to fulfill the household's demand for foreign goods. Furthermore, the presence of the importing firm enables the deriving of the law of one price gap as in the studies of Gali and Monacelli (2005), Monacelli (2005).

Differing from the domestic firm, the importing firm does not produce its goods. Instead, it imports goods from the foreign economy to fulfill the domestic demand for imported goods below.

$$
C_{F, t}(i)=\left[\frac{P_{F, t}(i)}{P_{F, t}}\right]^{-\varepsilon} C_{F, t}
$$

Similar to domestic firms, the importing firm also resets their price $\left(P_{F, t}(i)\right)$ according to the Calvo-style setting and indexation $\left(0<\gamma_{F}<1\right)$. Accordingly, a percentage $\left(1-\theta_{F}\right)$ of the firm can reset their price, whereas the rest $\theta_{F}$ adjust their price based on the following indexation rule

$$
P_{F, t}(i)=P_{F, t-1}(i) \pi_{F, t-1}^{\gamma_{H}} \text { and } \pi_{F, t-1}=\frac{P_{F, t-1}}{P_{F, t-2}}
$$


Solving the importing firm's optimization problem yields its real marginal cost such as

$$
m c_{F, t}(i)=\frac{e_{t} P_{F, t}^{*}(i)}{P_{F, t}}
$$

The above expression 3.4.3 implies that the real marginal cost is identical to cross importing firm. Thus, we can drop the index $i$. On the other hand, it is worth noting that $P_{F, t}^{*}=P_{t}^{*}$ in the foreign economy. Furthermore, the definition of the real exchange rate is

$$
Q_{t}=\frac{e_{t} P_{F, t}}{P_{t}}
$$

Therefore, the importing firm's real marginal cost in 3.4.3 can be intepretted as the law of one price gap, such as $\Psi_{t}=M C_{F, t}(i)$. This intepretation is identical to Gali and Monacelli (2005), Monacelli (2005). On the other hand, because of the Calvo-setting price, the Dixit-Stiglitz aggregate price of the importing firm will be.

$$
P_{F, t}=\left[\int_{0}^{1} P_{F, t}^{1-\varepsilon}(i) d i\right]^{\frac{1}{1-\varepsilon}}=\left[\theta_{F}\left(P_{F, t-1} \pi_{F, t-1}^{\delta_{F}}\right)^{1-\varepsilon}+\left(1-\theta_{F}\right)\left(P_{F, t}^{n e w}\right)^{1-\varepsilon} d i\right]^{\frac{1}{1-\varepsilon}}
$$

Finally, each importing firm will maximize its following expected present discounted profit subject to the demand curve in (3.4.1).

$$
\max _{P_{F, t}^{\text {new }}(i)} E_{t} \sum_{j=0}^{\infty}\left(\beta \theta_{F}\right)^{j}\left[\left(\frac{P_{F, t+j-1}(i)}{P_{F, t-2}(i)}\right)^{\delta_{F}} P_{F, t}^{\text {new }}(i)-P_{F, t+j} m c_{F, t+j}(i)\right] Y_{F, t+j}(i)
$$

The procedure for the optimization results in the following expression

$$
E_{t} \sum_{j=0}^{\infty}\left(\beta \theta_{F}\right)^{j} Y_{F, t+j}(i)\left[P_{F, t}^{n e w}(i)\left(\frac{P_{F, t+j-1}}{P_{F, t-1}}\right)^{\delta_{F}}-\frac{\varepsilon}{\varepsilon-1} P_{F, t+j} m c_{F, t+j}(i)\right]=0
$$

Taking a log-linear approximation of the above expression will lead to a hybrid New Keynesian Philip Curve for the importing firm.

$$
\widehat{\pi}_{F, t}=\frac{\beta}{1+\beta \delta_{F}} \widehat{\pi}_{F, t+1}+\frac{\delta_{F}}{1+\beta \delta_{F}} \widehat{\pi}_{F, t-1}+\frac{\left(1-\theta_{F}\right)\left(1-\beta \theta_{F}\right)}{\theta_{F}\left(1+\beta \delta_{F}\right)} \widehat{m c}_{F, t}+\widehat{\epsilon}_{c p, t}
$$

It is worth noting that the hybrid New Keynesian Philip Curve for the importing firm in 3.4 .8 implies that due to the presence of the nominal friction such as the sticky price, 
the exchange rate pass-through is incomplete. Indeed, its log-linear approximation of the law of one price gap in 3.4 .3 is

$$
\widehat{m c}_{F, t}=\widehat{e}_{t}+\widehat{P}_{t}^{*}-\widehat{P}_{F, t}
$$

\subsection{Foreign economy}

This paper uses a closed-economy DSGE model of Ireland (2011) to model the global economy. We do so because Vietnam is a small open economy. There is no spillover from this country to the foreign economy. This modelling strategy is identical to an influential study by Gali and Monacelli (2005), and other researches on the small open economy (see Buncic and Melecky (2008), Rees et al. (2016)).

There are four exogenous disturbances in the model of Ireland (2011). Two shocks to preference and cost-push follow the $\mathrm{AR}(1)$ process. Meanwhile, two remaining shocks to technology and policy follow the white noise. This modification gives three main advantages. The first one is to prevent the problem of singularity from the estimated model. This is because the total number of exogenous shocks is ten disturbances, whereas there are eight observed variables. The second advantage is to decompose the foreign structural shocks. In particular, the reduced-form BVAR model cannot reveal the structural disturbance. However, in the help of a DSGE model, the international structural shock is decomposed. The last advantage is to enhance the effects of the external shocks on the Vietnamese economy. This is because the number of shocks related to the external sector is seven, whereas there are three domestic disturbances (preference, technology, and monetary policy) in our structural model. This specification is especially relevant to Vietnam. This is because Vietnam has one of the highest degrees of openness in the world.

\subsection{Central bank}

To support the export sector, the central bank of Vietnam, known as the State Bank of Vietnam (SBV), has adopted a managed-float exchange rate regime. Accordingly, the fluctuations in the exchange rate of USD/VND are not highly volatile due to the interventions of this central bank (see Figure 4). Thus, modelling a monetary policy rule including the exchang rate is especially relevant to this emerging economy. 


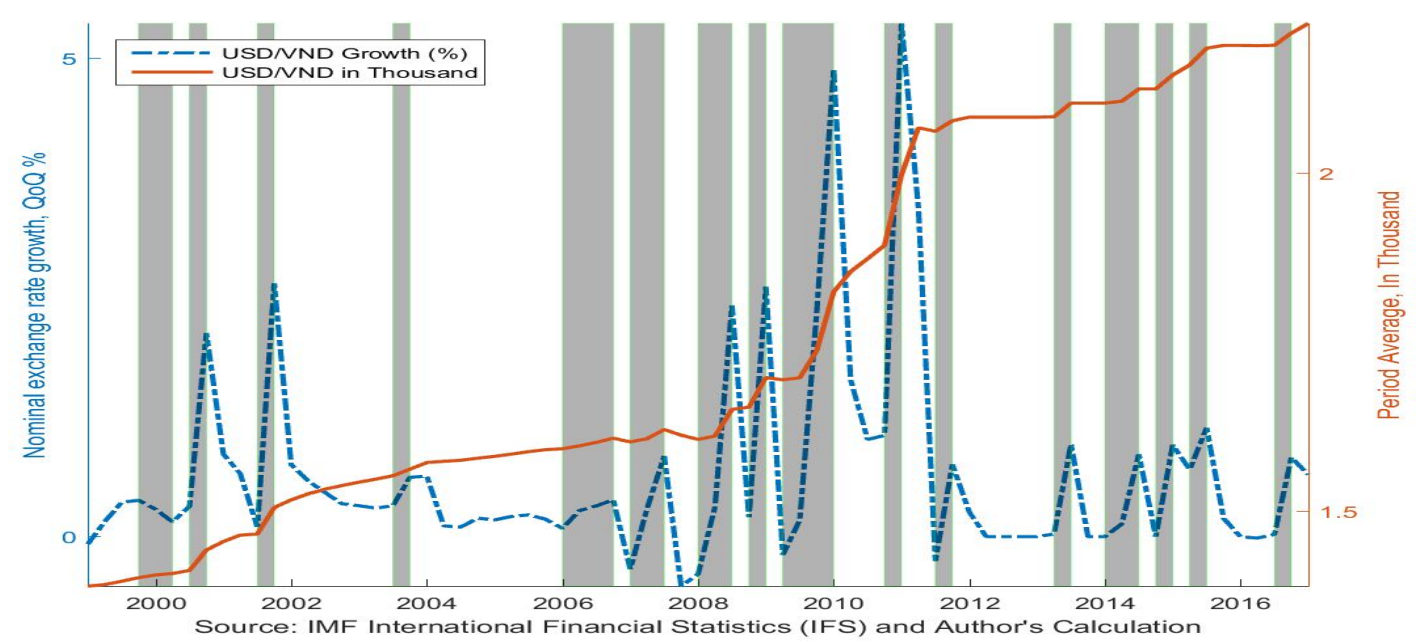

Accordingly, to close the model, the monetary policy rule is introduced as follows.

$$
\frac{i_{t}}{\bar{i}}=\left(\frac{i_{t-1}}{\bar{i}}\right)^{\psi_{i}}\left[\left(\frac{P_{t}}{P_{t-1}}\right)^{\psi_{\pi}}\left(\frac{Y_{t}}{\bar{Y}}\right)^{\psi_{y}}\left(\frac{Y_{t}}{Y_{t-1}}\right)^{\psi_{\Delta y}}\left(\frac{S_{t}}{S_{t-1}}\right)^{\psi_{s}}\right]^{\left(1-\psi_{i}\right)} \tilde{\varepsilon}_{m, t}
$$

where $\bar{i}$ and $\bar{Y}$ are steady-state values of nominal interest rate and output. The variable $\tilde{\varepsilon}_{m, t}$ denotes an exogenous monetary policy shock. The interest rate rule in the expression (3.6.1) indicates that central bank adjusts its policy rate according to changes in inflation $\left(P_{t} / P_{t-1}\right)$, output gap $\left(Y_{t} / \bar{Y}\right)$, output growth $\left(Y_{t} / Y_{t-1}\right)$ and the growth rate in the nominal exchange rate $\left(S_{t} / S_{t-1}\right)$.

\subsection{Exogenous shocks}

This model has ten exogenous disturbances. Moreover, it includes a higher number of foreign shocks than that of domestic disturbances. The advantages of this specification are discussed before. Domestic technology, preference, risk premium and cost-push, termof-trade shocks $\left(\tilde{\varepsilon}_{z, t}, \tilde{\varepsilon}_{g, t}, \tilde{\varepsilon}_{\phi, t}, \tilde{\varepsilon}_{t o t, t}, \tilde{\varepsilon}_{c p, t}\right)$ and two shocks in the foreign economy block, such as foreign preference $\left(\tilde{\varepsilon}_{a^{*}, t}\right)$ and cost-push $\left(\tilde{\varepsilon}_{c p^{*}, t}\right)$, are modeled as the first-order autoregressive process. On the other hand, three remaining shocks, domestic monetary policy $\left(\tilde{\varepsilon}_{i, t}\right)$, foreign technology $\left(\tilde{\varepsilon}_{c p^{*}, t}\right)$ and foreign monetary policy $\left(\tilde{\varepsilon}_{i^{*}, t}\right)$, follow the white noise process. It is worth noting that modelling the monetary policy shock as the white noise process is common in the standard literature (Smets and Wouters (2003), Adolfson et al. (2007), Justiniano and Preston (2010b), Ireland (2011)). Meanwhile, the strategy of modelling foreign technology shock closely follows Ireland (2011).

\subsection{Market Clearing Condition}

Beyond the domestic labor market, the three following markets must clear in equilibrium. First, the domestic bond market is cleared. Thus, $D_{t}=0$ for all $t$. Second, 
goods market clearing in the domestic economy requires that domestic output is equal to the sum of domestic consumption and foreign consumption of home produced goods (exports). Accordingly, it is given below.

$$
\begin{aligned}
Y_{t}^{d} & =C_{H, t}+C_{H, t}^{*} \\
Y_{t}^{*} & =C_{t}^{*}
\end{aligned}
$$

where the foreign demand for the domestically-made goods $\left(C_{H, t}^{*}\right)$ is depicted as

$$
C_{H, t}^{*}=\left(\frac{P_{H, t}^{*}}{P_{t}^{*}}\right)^{-\eta} Y_{t}^{*}=\left(\frac{P_{H, t}}{Q_{t} P_{t}}\right)^{-\eta} Y_{t}^{*} \text { and } Q_{t}=\frac{e_{t} P_{t}^{*}}{P_{t}}
$$

It is worth noting that we adopt the assumption of symmetric preferences across countries; here is domestic and foreign economies. This strategy is identical to Gali and Monacelli (2005).

Finally, as shown in Figure 3, the last market-clearing condition is the home country's international balance of payment. Indeed, this international balance of payment can be obtained from the domestic household's budget constraint in 3.2.1). In particular, we plug the following expressions into the budget constraint in (3.2.1): the domestic household's total consumption expenditure $P_{t} C_{t}=P_{H, t} C_{H, t}+P_{F, t} C_{F, t}$ and the domestic and importing firm's profits $\Pi_{H, t}=P_{H, t} C_{H, t}-W_{t} N_{t}, \Pi_{F, t}=P_{F, t} C_{F, t}-e_{t} P_{t}^{*} C_{F, t}$. Moreover, since the domestic bond market clearing holds, $D_{t}=0$ for all $t$. As a result, it is given below.

$$
\begin{gathered}
P_{H, t} C_{H, t}^{*}-e_{t} P_{t}^{*} C_{F, t}=e_{t} B_{t}-e_{t} B_{t-1}\left[1+\tilde{i}_{t-1}^{*}\right] \phi\left(A_{t}\right) \\
\text { where: } \phi\left(A_{t}\right)=\exp \left[-\chi\left(A_{t}+\tilde{\phi}_{t}\right)\right] \text { and } A_{t}=\frac{\tilde{e}_{t-1} B_{t-1}}{\bar{Y} P_{t-1}}
\end{gathered}
$$

It is worth noting that the left-hand side in the equation $(3.8 .3)$ is interpreted as the net trade balance, whereas the right-hand side is the net capital account in the international balance of payment.

\subsection{How do structural shocks impact domestic variables?}

Before taking data into this model, we theoretically analyze how ten structural shocks impact the domestic aggregate economic fluctuations? Thus, the log-linear approximation is used.

At first, the New Keynesian IS curve represents the demand side.

$$
c_{t}-h c_{t-1}=E_{t}\left[c_{t+1}-h c_{t}\right]-\frac{1-h}{\sigma}\left(i_{t}-E_{t} \pi_{t+1}\right)+\frac{1-h}{\sigma}\left(\varepsilon_{g, t}-E_{t} \varepsilon_{g, t+1}\right)
$$

If we eliminate the habit formation parameter in the expression (3.9.1), the usual 
Euler equation is obtained. Moreover, it is clear that an increase in real interest rate, $\left(i_{t}-E_{t} \pi_{t+1}\right)$, declines the current consumption, $\left(c_{t}\right)$, and this decline in consumption is governed by $(1-h) / \sigma(1+h)$. On the other hand, the preference shock $\left(\varepsilon_{g, t}\right)$ positively influences the current consumption.

Second, the connection of domestic consumption and output, $\left(c_{t}, y_{t}\right)$, with foreign output, $\left(y_{t}^{*}\right)$, is established via the log-linear approximation of the goods market clearing condition as below

$$
y_{t}=(1-\alpha) c_{t}+\alpha \eta(2-\alpha) s_{t}+\alpha \eta \psi_{F, t}+\alpha y_{t}^{*}
$$

where the LOOP gap, $\psi_{F, t}$, is measured as the difference between foreign price and imported-goods price as below

$$
\psi_{F, t}=\left(e_{t}+p_{t}^{*}\right)-p_{F, t}
$$

The expression $(3.9 .2)$ indicates that an increase in foreign output leads to a rise in domestic output, but a fall in consumption. This effect is identical to the impact of the LOOP gap, $\psi_{F, t}$. Therefore, an adverse foreign inflation shock and depreciation in the nominal exchange rate increase domestic output but decrease consumption. Moreover, the influences of the term of trade, $\left(s_{t}\right)$, on domestic output and consumption are clearly shown in the expression 3.9 .2 . On the other hand, the change in the term of trade has a log-linear form and presents the difference between imported-goods price inflation, $\pi_{F, t}$, and domestic-goods price inflation, $\pi_{H, t}$, as below.

$$
\Delta s_{t}=\pi_{F, t}-\pi_{H, t}+\varepsilon_{t o t, t}
$$

It is worthwhile noting that in the specification of the term of trade above, the term $\left(\varepsilon_{t o t, t}\right)$ is a shock to the term of trade. Accordingly, it is modeled as an AR(1) process as such $\varepsilon_{t o t, t}=\rho_{t o t} * \varepsilon_{t o t, t-1}+\epsilon_{t o t, t}$. This simple specification would provide two advantages. The first advantage is, as mentioned before, that we would examine the issue of concern of how important the term of trade is to the Vietnamese economy. This is because this impact would be one of the interesting issues in the current literature on the developing and emerging markets (Mendoza (1995), Kose (2002), Schmitt-Grohé and Uribe (2018)). The second advantage is to prevent the problem of the singularity in our model.

Third, the volatilities of the real exchange rate, $q_{t}$, are impacted by the term of trade and the LOOP gap as below

$$
q_{t}=\left(e_{t}+p_{t}^{*}\right)-p_{t}=\psi_{F, t}+(1-\alpha) s_{t}
$$

Fourth, the domestic-goods price inflation, $\pi_{H, t}$, is depicted as a Hybrid New Keynesian Phillip Curve of the domestic firm as following.

$$
\pi_{H, t}=\frac{\beta}{1+\beta \theta_{H}} E_{t} \pi_{H, t+1}+\frac{\delta_{H}}{1+\beta \theta_{H}} \pi_{H, t-1}+\frac{\left(1-\theta_{H}\right)\left(1-\beta \theta_{H}\right)}{\theta_{H}\left(1+\beta \theta_{H}\right)} m c_{t}
$$


As shown in the expression (3.9.5), the current domestic-goods price inflation depends on not only past but also future inflations. Moreover, change in the current domestically made-goods inflation is influenced by three foreign sources: foreign output, exchange rate and term of trade. These sources have direct or indirect impacts via their effects on real marginal cost, $m c_{t}$, as such.

$$
m c_{t}=\varphi y_{t}-(1+\varphi) \varepsilon_{a, t}+\alpha s_{t}+\frac{\sigma}{1-h}\left(c_{t}-h c_{t-1}\right)
$$

Fifth, the imported-goods price inflation, $\pi_{F, t}$ is described as the Hybrid New Keynesian Phillip Curve of importing firm as follows.

$$
\pi_{F, t}=\frac{\beta}{1+\beta \theta_{F}} \pi_{F, t-1}+\frac{\delta_{F}}{1+\beta \theta_{F}} E_{t} \pi_{F, t+1}+\frac{\left(1-\theta_{F}\right)\left(1-\beta \theta_{F}\right)}{\theta_{F}\left(1+\beta \theta_{F}\right)} \psi_{t}+\varepsilon_{c p, t}
$$

Similar to the domestic-goods price inflation, as in the expression (3.9.7), the importedgoods price inflation, $\pi_{F, t}$, depends on not only past but also future inflations. Moreover, it is impacted by the LOOP gap, $\psi_{t}$, and the cost-push shock, $\varepsilon_{c p, t}$.

Sixth, the domestic CPI inflation is associated with the domestic-goods price inflation and term of trade as follows.

$$
\pi_{t}=\pi_{H, t}+\alpha \Delta s_{t}
$$

Seventh, taking the log-linear approximation of the expression (3.6.1) to yield the following uncovered interest rate parity.

$$
\left(i_{t}-E_{t} \pi_{t+1}\right)-\left(i_{t}^{*}-E_{t} \pi_{t+1}^{*}\right)=E_{t} \Delta q_{t}-\chi a_{t}-\phi_{t}
$$

Eighth, the log-linear approximation of the international balance of payment in the equation 3.8 .3 is below.

$$
y_{t}-c_{t}-\alpha\left(s_{t}+\psi_{F, t}\right)=a_{t}-\beta^{-1} a_{t-1}
$$

Finally, the policy rule in 3.6 .1 is approximated as

$$
\widehat{i}_{t}=\psi_{i} \widehat{i}_{t-1}+\left(1-\psi_{i}\right)\left[\psi_{\pi} \widehat{\pi}_{t}+\psi_{y} \widehat{y}_{t}+\psi_{\Delta y} \widehat{\Delta y}_{t}+\psi_{e} \widehat{\Delta e}_{t}\right]+\widehat{\varepsilon}_{M, t}
$$

As shown in (3.9.11), the central bank adjusts its policy interest rate in response to the past interest rate $\left(i_{t-1}\right)$, CPI inflation $\left(\pi_{t}\right)$, output gap $\left(y_{t} / \bar{y}\right)$, output growth $\left(\Delta y_{t}\right)$, and growth in nominal exchange rate $\left(\Delta e_{t}\right)$. The disturbance $\left(\varepsilon_{M, t}\right)$ denotes the monetary policy shock. 


\section{Model solution, data and estimation strategy}

\subsection{Model solution}

This model has eleven endogenous variables: consumption $\left(c_{t}\right)$, output $\left(y_{t}\right)$, interest rate $\left(i_{t}\right)$, real exchange rate $\left(q_{t}\right)$, term of trade $\left(s_{t}\right)$, CPI inflation $\left(\pi_{t}\right)$, domestic-goods price inflation $\left(\pi_{H, t}\right)$, imported-goods price inflation $\left(\pi_{F, t}\right)$, the LOOP gap $\left(\psi_{F, t}\right)$, the real quantity outstanding foreign bond $\left(a_{t}\right)$, and domestic real marginal cost $\left(m c_{t}\right)$. To solve for these eleven endogenous variables, eleven above log-linear approximation equations, from (3.9.1) to (3.9.11), are used. Furthermore, this model has five foreign economy variables corresponding to the foreign economy block (see Section 3.5).

It is worthwhile noting that the number of external-related shocks accounts for the dominant proportion. In particular, there are ten structural shocks in total, with seven external-related disturbances. This specification would enhance the effects of the foreign economy on this emerging country with one of the most open economies in the world. On the other hand, it also prevents the problem of the singularity in the underlying model. This is because the number of exogenous disturbances is higher than the number of observed variables.

\subsection{Data}

In this paper, we use five Vietnamese macroeconomic variables and three foreign economy variables. The period of $1999 Q 1-2017 Q 1$ is chosen because of the available data on this emerging country. The Vietnamese variables include CPI-deflated output growth, CPI inflation, policy interest rate, the real exchange rate, and terms of trade. The quarterly data on output growth is provided by the General Statistics Office (GSO) of Vietnam. On the other hand, four remaining Vietnamese variables are collected from the IMF IFS's online database. Meanwhile, three US macroeconomic variables are used as the proxy for the foreign economy. We do this because in the literature on the small open economy, the US economy is typically treated as the foreign one (see Buncic and Melecky (2008), Choi and Hur (2015), Gabriel et al. (2016), and Rees et al. (2016)). All data sources are presented in Appendix A. In addition, it is worth noting that in this paper, we do not detrend or demean the data before estimation. Instead, we will do this within the estimation procedure by including intercepts in the measurement equations. Finally, the data used for estimation is presented in Figure 5 below. 

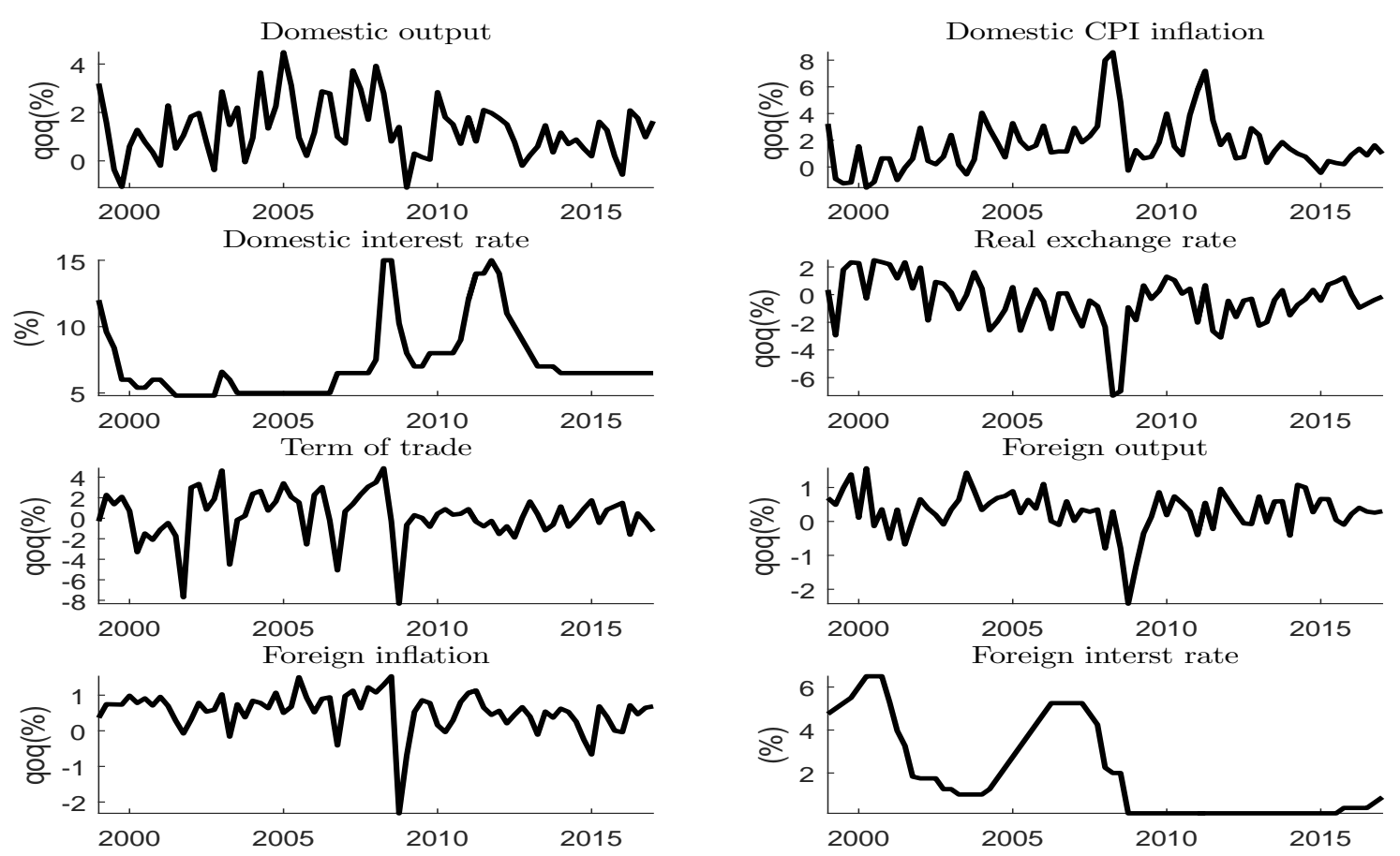

Figure 5: The quarterly data about the Vietnamese and foreign economies

\subsection{Forming the posterior density}

The theoretical log-linearized model, which is described in section 4.2 , will be linked to the actual data via the measurement equation system in appendix $B$. These two equation systems can then be summarized in a state-space framework below.

The state equation

The observed equation

$$
\begin{array}{r}
\Omega_{t}=A \Omega_{t-1}+B \varepsilon_{t} \\
\Phi_{t}=C \Phi_{t-1}+D \Omega_{t}+F \epsilon_{t} \\
\varepsilon_{t} \sim N\left(0, I_{q}\right) \text { and } \epsilon_{t} \sim N\left(0, I_{r}\right)
\end{array}
$$

where $\Omega_{t}$ is the m-dimensional vector of model variables or state vector and $\Phi_{t}$ is an n-dimensional vector of observed variables. Based on the state space system, the loglikelihood, $\ln L=\ln p\left(\Phi_{t} \mid \Theta\right)$, can be computed with the Kalman filter and $\Theta$ presents the matrix of parameters $A, B, C, D, F, I_{q}$ and $I_{r}$.

The Bayes theorem enables the combining of prior and likelihood distributions. In particular, the posterior density, $p\left(\Theta \mid \Phi_{t}\right)$, is proportional, $\propto$, to the product of prior distribution, $p(\Theta)$, and likelihood function, $p\left(\Phi_{t} \mid \Theta\right)$, as in the following formula

$$
p\left(\Theta \mid \Phi_{t}\right) \propto p(\Theta) p\left(\Phi_{t} \mid \Theta\right)
$$

In terms of the log form, the posterior density in 4.3.4 will be 


$$
\begin{aligned}
\ln p\left(\Theta \mid \Phi_{t}\right) & \propto \ln p(\Theta)+\ln p\left(\Phi_{t} \mid \Theta\right) \\
& \propto \ln p(\Theta)+\ln L
\end{aligned}
$$

It is worth noting that the conditional posterior density $p\left(\Theta \mid \Phi_{t}\right)$ is typically a complex form. Thus, we can not directly sample from this density. To address this issue, we use the Metropolis-Hastings sampling algorithm. Accordingly, we will generate the number of random values $(\vartheta)$ from a proposal density. Indeed, this proposal distribution is a multivariate normal density as follows.

$$
q\left(\vartheta \mid \Theta^{i-1}\right) \sim \mathbf{N}\left(\Theta^{i-1}, c^{2} \Sigma\right)
$$

Where the covariance matrix $\Sigma$ is typically the negative of the inverse Hessian at the mode of the conditional posterior density $p\left(\Theta \mid \Phi_{t}\right)$ in (4.3.4). A candidate $\vartheta$, which is randomly generated from the above density, leads to an increase in the conditional posterior density such as $p\left(\vartheta \mid \Phi_{t}\right) p\left(\Theta^{i-1} \mid \Phi_{t}\right)$. It is then accepted that $\Theta^{i}=\vartheta$. Otherwise, it is rejected and $\vartheta=\Theta^{i-1}$. Thus, we typically control the parameter $c$ to get a designed acceptance ratio. This acceptance ratio is computed below.

$$
\text { The acceptance ratio }=\frac{\text { A number of accepted draws }}{\text { A total number of proposal draws }}
$$

\section{Estimation}

There are only three parameters which are fixed before estimation. The first two parameters associated with both domestic and foreign economy discount factors are calibrated according to the standard literature on the real business cycle. For example, the first parameter is the domestic discount factor $(\beta=0.99)$. The second parameter is the foreign economy discount factor $\left(\beta^{*}=0.9987\right)$. The last parameter is the foreign Phillip curve $\left(\psi^{*}=0.10\right)$ which is identical to Ireland (2011). Thus, in this paper, 38 structural parameters and eight nonstructural parameters associated with measurement errors are identified and estimated within the underlying model by using the Bayesian technique.

\subsection{Prior Information}

The prior densities for 38 estimated structural and 8 non-structural parameters are mainly based on the previous literature. The second column in Table 1 gives an overview of prior information. Because of space constraint, we shortly introduce the discussions about these prior densities. The detailed discussions can be found in the supplemental material.

In general, this paper uses four types of the prior distribution. They are the beta, gamma, inverse-gamma, and uniform densities. Accordingly, the beta distribution is used for the degree of openness, inverse Frisch, consumption habit, Calvo price, indexation, 
and persistent shock parameters. Meanwhile, the gamma distributions are applied to parameters in the Taylor rule. On the other hand, the inverse-gamma distribution is applied to the parameters associated with risk premium, domestic and imported goods substitute elasticities and the standard deviation of ten structural disturbances. Finally, the uniform densities are used for eight non-structural parameters of intercepts in the measurement equation. The further discussions are given below.

We use the gamma distribution with a mean of 0.6 and a standard deviation of 0.05 as the prior density for the degree of openness $(\alpha)$. On the other hand, based on the studies by Schmitt-Grohé and Uribe (2003), Adolfson et al. (2007), Justiniano and Preston (2010b), we impose the inverse gamma distribution with a mean of 0.01 and a standard deviation of infinity as a prior density for risk premium elasticity $\chi$. There are two advantages of using this prior specification. First, the prior standard deviation of infinity would create more flexibility in estimation. Second, it is uninformative regarding this parameter in the case of Vietnam. This prior strategy is identical to the frontier study of García-Cicco et al. (2010). Indeed, García-Cicco et al. (2010) use the uniform density as the prior distribution for all estimated parameters, including the parameter of risk premium elasticity, $\chi$.

Based on the studies by Havranek et al. (2015), the prior inverse value of elasticities of intertemporal substitution, $\sigma$, follows the gamma distribution with a mean of 1.2 and a standard deviation of 0.4. Meanwhile, the magnitude of the inverse Frisch elasticity of labor supply $(\varphi)$ is a controversial issue in macroeconomics (Christiano et al. (2010). Due to the high fraction of a number of under-35-year-old people in Vietnam, we believe that the Frisch elasticity of labor supply, $(1 / \varphi)$, would be large. A high value of the Frisch elasticity of labor supply reflects the strong response of labor supply to wage and the properties of aggregate data. Thus, we use the gamma distribution with a mean of 0.5 and a standard deviation of 0.25 as the prior inverse value, $(\varphi)$.

On the other hand, according to the standard literature on the real business cycle, price changes every four months. Furthermore, typically, the degree of Calvo price is lower in the importing firm than domestic firm. However, in this paper, the prior density is identical to these two firms. This prior strategy is identical to Justiniano and Preston (2010b). Thus, we use the beta distribution with a mean of 0.75 and a standard deviation of 0.1 as the prior density for $\theta_{H}$ and $\theta_{F}$.

In the literature, habit formation varies widely across countries and data types. Accordingly, this estimated parameter is typically higher in the macro level than micro level (see Fuhrer (2000), Christiano et al. (2005), Havranek et al. (2017)). For Vietnam, we therefore use the beta distribution with a mean of 0.6 and a standard deviation of 0.1 as the prior density for this parameter. On the other hand, the two parameters for price indexation, $\delta_{H}$ and $\delta_{F}$, enable us to describe the inflation dynamic as backward- and forward-looking behavior (Gali and Gertler (1999), Galí et al. (2005), Christiano et al. (2005), Smets and Wouters (2007)). Based on the standard literature, we use the beta distribution with a mean of 0.5 and standard deviation of 0.25 as the prior density for these two parameters.

Taylor (2000) and Garcia et al. (2011) argued that including the exchange rate in the 
monetary policy rule is significantly crucial in the case of the developing and emerging economies. Furthermore, like other developing Asian countries, Vietnam mainly depends on exports and adopts a partial float exchange rate regime. Thus, the inclusion of the exchange rate in the Taylor rule would give a significant improvement to modelling the policy interest rate. On the other hand, Figure 5 shows that the policy interest rate in Vietnam is not as volatile as inflation, output, and real exchange rate over the period 1999Q1-2017Q1. This implies that the policy rule should include a smoothing parameter, $\psi_{i}$. Since this smoothing parameter is in the range $(0-1)$, we use the beta distribution with a mean of 0.75 and standard deviation of 0.25 as prior density. We set the gamma distribution with a mean of 1.5 and standard deviation of 0.25 for the parameter of inflation, $\psi_{\pi}$. Hence, this value ensures that our model does not suffer from the issue of indeterminacy. The three remaining parameters, output gap, output growth, and exchange rate, $\left(\psi_{y}, \psi_{\Delta y}, \psi_{\Delta e}\right)$, follow the gamma distribution with a mean of 0.5 and a standard deviation of 0.25 .

The foreign economy block has 13 parameters to be estimated. Indeed, these 13 parameters are priors as one of three distributions (gamma, beta, and inverse gamma). For instance, the inverse gamma density is used as the prior distribution for all four shock innovations. Meanwhile, their persistent parameters are priors as the beta density. An exception for the smoothing parameter is that the three remaining parameters in the foreign monetary policy rule are priors as the gamma distribution. It is worth noting that Ireland (2011) calibrated the steady-state growth. In this paper, however, this parameter is estimated with its prior density of the gamma distribution. Finally, both foreign habit and price indexation are priors as the beta distribution.

\subsection{Estimated results and discussions}

The majority of 49 theoretical model parameters will be estimated using the Bayesian technique. Based on the state-space form, the log-likelihood function is evaluated using the Kalman filter. Afterward, several optimization algorithms are used to find the mode of the posterior density $p\left(\Theta \mid \Phi_{t}\right)$ in (4.3.5). Using this mode, we propose a multivariate normal distribution $q\left(\vartheta \mid \Theta^{i-1}\right)$ in (4.3.6). Then, we generate 300,000 draws from this proposal density. On the other hand, we specify the parameter $c$ to target an acceptance rate of around $30 \%$. Indeed, this value is typically used in the literature. Meanwhile, we determine 75, 000 discards. Indeed, this estimation procedure of the Markov Chain Monte Carlo (MCMC) method with the Metropolis-Hastings algorithm is conducted by using the DYNARE Toolbox of Adjemian et al. (2011).

In this paper, we use an estimated small open economy NK-DSGE model for policy analysis. Thus, all estimated model parameters should bear both statistical and economic meanings. Therefore, in this section, we briefly interpret the estimated results. Accordingly, we find that the data is very informative for most estimated parameters. As an example, the prior density significantly differs from its posterior distribution (see Figures 15,17 in Appendix C). On the other hand, Table 1 presents the detail of estimation. 
Meanwhile, Figure 6 shows the predicted values and actual data. Indeed, the predicted values present the Kalman filtered one-sided estimate of the observed variables. Accordingly, the estimated result of the Taylor rule and domestic CPI inflation dynamics for Vietnam is one of the most striking estimations. For instance, there are small differences between fitted and actual data. Other predicted values, such as real exchange rate and output, include some points which differ from their actual data in magnitude. However, overall, they still share the key trend of movement in common with actual data.

Figure 6: Actual and its fitted values
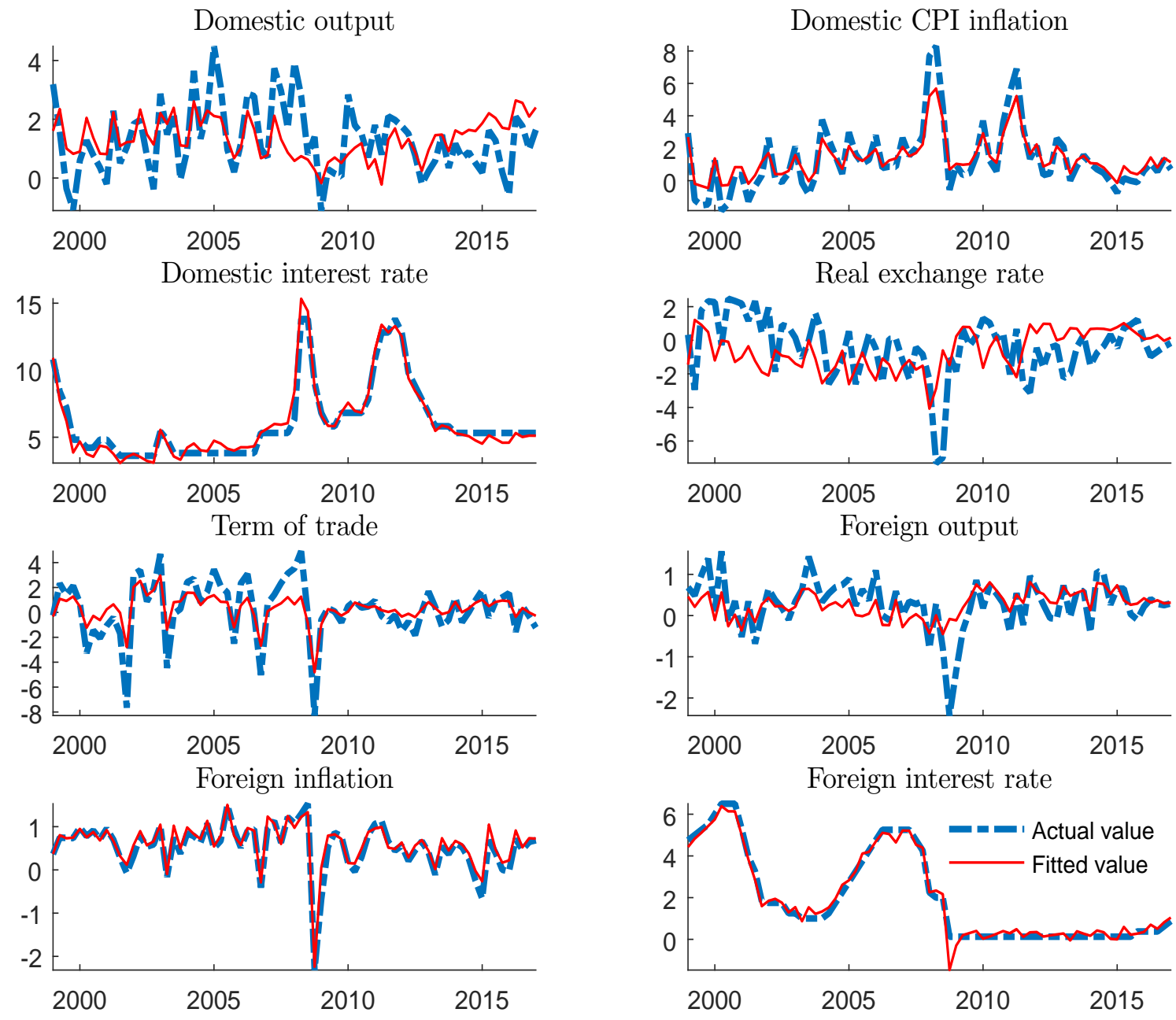

The comparison between fitted values and actual data is one of the good criteria to assess how an estimated model fits data well. However, in the current literature on estimating the NK-DSGE model, not every study reports this result, even in the most influential study by Smets and Wouters $(2003)$. On the other hand, it's fair to say that it is difficult to have a model that can generate its predicted values perfectly fitting actual data. As an example, in a well-known study by Adolfson et al. (2007), the predicted value could not fit the European data perfectly well either, in particular real wage, import, and world output. Other studies by the economists at the Reserve Bank of Australia also shared the same problem. In particular, the fitted values of non-farm GDP and export share of GDP significantly differ from their actual data on Australia in the study by 
Nimark (2009). A similar pattern is also found in the study by Jääskelä and Nimark (2011). More specifically, the fitted values of real wage, investment, employment, export, and import commodity export differed considerably from their actual data on Australia. Therefore, we argue that our estimated model fits data on the Vietnamese and foreign economies relatively well.

Due to space constraint, we present a brief discussion about selected parameters. The detailed information can be found in the supplemental material.

The estimated mean of the debt elasticity parameter $\chi$ is 0.004 . This estimated result is as small as what we expect. Futhermore, it is located in the range that is shared with the standard literature (Schmitt-Grohé and Uribe (2003), Adolfson et al. (2007), Justiniano and Preston (2010b)). The presence of this parameter reflects imperfect capital mobility in Vietnam. This issue leads to the failure of the Uncovered Interest Rate Parity. Thus, the difference between the real interest rate in Vietnam and its counterpart in the U.S economy is not identical to change in the exchange rate $(U S D / V N D)$.

Two estimated Calvo prices are 0.86 for the domestic firm and 0.49 for the importing firm. This implies that in Vietnam the frequency of changing price is every seven quarters in the case of the domestic firm, whereas it is around every two quarters in the case of the importing firm. We see that in Vietnam the domestic firm's price is much stickier than the importing firm's local-currency price. This fact is not only in the case of Vietnam but also in other advanced nations including Euro, Canada and Australia Adolfson et al. (2007), Justiniano and Preston (2010b)). The intuitive explanation is that the importing firm's local-currency price is strongly influenced by the volatilities of the exchange rate, but not for the domestic firm.

The posterior mean of price indexation is small, such as $\delta_{H}=0.06$ and $\delta_{F}=0.30$. Such a small posterior value is identical to that in the pioneer and influential study by Gali and Gertler (1999) on the hybrid New Keynesian Phillip curve. For example, these authors argued: "While the benchmark pure forward-looking model is rejected on statistical grounds, it appears still to be a reasonable first approximation of reality". However, we still argue that an appropriate method of modelling the inflation dynamic for Vietnam should account for not only expected future inflation but also its past. This is because the CPI inflation in Vietnam tends to be higher than in advanced nations.

Regarding the Taylor rule, an estimated value of smoothing parameter, $\psi_{i}$, is 0.89 . This implies that the policy interest rate in Vietnam is highly persistent. This estimated value captures well the fact that this policy rate is not as volatile as inflation, output growth, and exchange rate (see Figure 5). On the other hand, an estimated parameter of 1.03 for inflation differs slightly from unity. Thus, we argue that the SBV pursued the moderately anti-inflation policy over the period of 1999Q1 to 2017Q1. Indeed, there are two striking opposite episodes of inflation during this stage. The first one took place in the early 2000s. Accordingly, the Vietnamese economy suffered from deflation (2000: $-1.70 \%$; 2001: $-0.43 \%$ ). Thus, the SBV pursued the anti-deflation strategy. Conversely, the second episode took place during and after the 2008-global recession. In particular, the Vietnamese economy faced the two-digit inflation (2008: $23.116 \% ; 2011$ : 18.676\%). 
Therefore, the SBV pursued the anti-inflation strategy.

Meanwhile, two estimated values for output, $\psi_{y}$ and $\psi_{\Delta y}$, are 0.19 and 0.92 . This implies that the SBV adjusts its policy interest rate more strongly in response to output growth rather than the output gap. A similar pattern takes place in several advanced nations, such as Australia, Canada, and New Zealand (see Justiniano and Preston (2010b)).

Moreover, the estimated value for the coefficient associated with the exchange rate in the Taylor rule is the most striking difference from that in other advanced countries. Specifically, this estimated value, $\psi_{\Delta e}$, is 0.81 in Vietnam. This value is significantly higher than that in advanced nations. For example, Adolfson et al. (2007) estimated this parameter to be -0.0009 for the euro area. Meanwhile, Justiniano and Preston (2010b) found 0.29, 0.29, and 0.07 for Canada, Australia, and New Zealand, respectively. This fact can attribute to the difference in the exchange rate regime in Vietnam and these advanced countries. Accordingly, the SBV has adopted a managed-float exchange rate, whereas the exchange rate is freely floated in advanced nations. Indeed, the fluctuations in the exchange rate (USD/VND) are managed within a band which is set by this central bank. Thus, such a highly estimated value for the coefficient of the exchange rate, $\psi_{\Delta e}$, would confirm the vital role of the presence of the exchange rate in modelling policy rule in emerging economies (Taylor (2000) and Garcia et al. (2011)). 
Table 1: Prior densities and posterior estimates

\begin{tabular}{|c|c|c|c|c|c|c|c|c|}
\hline \multirow[t]{2}{*}{ Parameters } & & \multicolumn{3}{|c|}{ Prior densities } & \multicolumn{4}{|c|}{ Posterior densities } \\
\hline & & Type & Mean & SD & Mean & SD & Lower & Upper \\
\hline Degree of openness & $\alpha$ & B & 0.60 & 0.05 & 0.556 & 0.051 & 0.4668 & 0.6329 \\
\hline Risk premium elasticity & $\chi$ & I & 0.01 & $\inf$ & 0.004 & 0.001 & 0.0022 & 0.0055 \\
\hline $\begin{array}{l}\text { Inverse intertemporal } \\
\text { elasticity of substitution }\end{array}$ & $\sigma$ & G & 1.20 & 0.40 & 1.026 & 0.282 & 0.5824 & 1.5011 \\
\hline Inverse Frisch & $\varphi$ & B & 0.50 & 0.25 & 0.552 & 0.239 & 0.1750 & 0.9428 \\
\hline Calvo domestic price & $\theta_{H}$ & B & 0.75 & 0.10 & 0.858 & 0.016 & 0.8335 & 0.8839 \\
\hline Calvo import price & $\theta_{F}$ & B & 0.75 & 0.10 & 0.494 & 0.068 & 0.3762 & 0.6004 \\
\hline Elasticity H-F goods & $\eta$ & I & 1.50 & $\inf$ & 0.628 & 0.096 & 0.4763 & 0.7766 \\
\hline Habit & $h$ & B & 0.60 & 0.10 & 0.593 & 0.078 & 0.4661 & 0.7174 \\
\hline Domestic price indexation & $\delta_{H}$ & B & 0.50 & 0.25 & 0.063 & 0.046 & 0.0006 & 0.1210 \\
\hline Foreign price indexation & $\delta_{F}$ & B & 0.50 & 0.25 & 0.301 & 0.182 & 0.0160 & 0.5750 \\
\hline Taylor rule, smoothing & $\psi_{i}$ & $\mathbf{B}$ & 0.50 & 0.25 & 0.885 & 0.021 & 0.8511 & 0.9194 \\
\hline Taylor rule, inflation & $\psi_{\pi}$ & G & 1.50 & 0.25 & 1.030 & 0.183 & 0.7045 & 1.3134 \\
\hline Taylor rule, output & $\psi_{y}$ & G & 0.50 & 0.25 & 0.187 & 0.056 & 0.1057 & 0.2780 \\
\hline Taylor rule, output growth & $\psi_{\Delta y}$ & G & 0.50 & 0.25 & 0.916 & 0.349 & 0.3263 & 1.3940 \\
\hline Taylor rule, exchange rate & $\psi_{\Delta e}$ & G & 0.50 & 0.25 & 0.810 & 0.301 & 0.2773 & 1.1821 \\
\hline Technology shock, persistent & $\rho_{z}$ & B & 0.80 & 0.10 & 0.630 & 0.074 & 0.5131 & 0.7473 \\
\hline Preference shock, persistent & $\rho_{g}$ & B & 0.80 & 0.10 & 0.772 & 0.067 & 0.6626 & 0.8734 \\
\hline Import cost-push shock, persistent & $\rho_{c p}$ & B & 0.80 & 0.10 & 0.929 & 0.029 & 0.8874 & 0.9766 \\
\hline Risk premium shock, persistent & $\rho_{r p}$ & B & 0.80 & 0.10 & 0.928 & 0.028 & 0.8839 & 0.9727 \\
\hline sd technology & $\sigma_{z}$ & $\mathbf{I}$ & 0.50 & inf & 20.00 & 1.098 & 18.899 & 21.579 \\
\hline sd preference & $\sigma_{g}$ & I & 0.50 & inf & 11.66 & 2.819 & 7.1927 & 16.472 \\
\hline sd import cost-push & $\sigma_{c p}$ & I & 0.50 & $\inf$ & 1.602 & 0.575 & 0.6555 & 2.5220 \\
\hline sd risk premium & $\sigma_{r p}$ & $\mathbf{I}$ & 0.50 & inf & 0.292 & 0.065 & 0.1750 & 0.3861 \\
\hline sd term of trade & $\sigma_{t o t}$ & $\bar{U}$ & 0.00 & 10.0 & 1.263 & 0.504 & 0.3615 & 2.0391 \\
\hline sd policy & $\sigma_{m}$ & I & 0.50 & $\inf$ & 0.366 & 0.050 & 0.2821 & 0.4314 \\
\hline Foreign steady state growth & $\rho_{z *}$ & G & 1.003 & 0.13 & 0.901 & 0.107 & 0.7306 & 1.0741 \\
\hline Foreign habit & $\mathrm{h}^{*}$ & B & 0.40 & 0.10 & 0.530 & 0.071 & 0.4131 & 0.6494 \\
\hline Foreign persistent cost-push & $\rho_{p *}$ & B & 0.80 & 0.10 & 0.679 & 0.103 & 0.5107 & 0.8527 \\
\hline Foreign persistent preference & $\rho_{a *}$ & B & 0.80 & 0.10 & 0.875 & 0.044 & 0.8075 & 0.9411 \\
\hline Foreign price indexation & $\alpha^{*}$ & B & 0.75 & 0.10 & 0.446 & 0.110 & 0.2670 & 0.6266 \\
\hline Foreign policy rule, smoothing & $\rho_{i *}$ & B & 0.60 & 0.20 & 0.904 & 0.015 & 0.8790 & 0.9278 \\
\hline Foreign policy rule, inflation & $\rho_{i p *}$ & G & 1.50 & 0.25 & 1.427 & 0.182 & 1.1181 & 1.7127 \\
\hline Foreign policy rule, output gap & $\rho_{i y *}$ & G & 0.50 & 0.25 & 0.153 & 0.047 & 0.0796 & 0.2276 \\
\hline Foreign policy rule, output growth & $\rho_{\Delta y *}$ & G & 0.50 & 0.25 & 0.832 & 0.249 & 0.4248 & 1.2078 \\
\hline sd foreign policy & $\overline{\sigma_{i *}}$ & $\mathbf{I}$ & 0.160 & inf & 0.111 & 0.011 & 0.0942 & 0.1286 \\
\hline sd foreign preference & $\sigma_{a *}$ & $\mathbf{I}$ & 0.08 & inf & 2.948 & 0.615 & 1.9774 & 3.8368 \\
\hline sd foreign cost-push & $\sigma_{c p *}$ & $\mathbf{I}$ & 0.002 & inf & 0.367 & 0.074 & 0.2401 & 0.4852 \\
\hline sd foreign technology & $\sigma_{z *}$ & I & 0.009 & $\inf$ & 0.010 & 0.050 & 0.0075 & 0.0211 \\
\hline Mean domestic output & $\mu_{y}$ & $\mathbf{U}$ & 0.00 & 10.0 & 1.440 & 0.060 & 1.3479 & 1.5382 \\
\hline Mean domestic inflation & $\mu_{\pi}$ & $\mathrm{U}$ & 0.00 & 10.0 & 1.772 & 0.515 & 0.9318 & 2.6597 \\
\hline Mean real exchange rate & $\mu_{q}$ & $\mathrm{U}$ & -1.0 & 0.00 & -0.554 & 0.129 & -0.7157 & -0.2892 \\
\hline Mean term of trade & $\mu_{t o t}$ & $\mathrm{U}$ & 0.00 & 10.0 & 0.168 & 0.122 & 0.0000 & 0.4385 \\
\hline Mean domestic rate & $\mu_{i}$ & $\mathrm{U}$ & 0.00 & 15.0 & 7.939 & 2.304 & 3.8651 & 11.0264 \\
\hline Mean foreign inflation & $\mu_{\pi *}$ & $\mathrm{U}$ & 0.00 & 10.0 & 0.610 & 0.109 & 0.4099 & 0.9885 \\
\hline Mean foreign output & $\mu_{y *}$ & $\mathrm{U}$ & 0.00 & 10.0 & 0.304 & 0.035 & 0.2124 & 0.3173 \\
\hline Mean foreign rate & $\mu_{i *}$ & $\mathrm{U}$ & 0.00 & 10.0 & 2.814 & 1.624 & 0.7337 & 3.7025 \\
\hline
\end{tabular}

Distribution: $\boldsymbol{B}$, beta; $\boldsymbol{G}$, gamma; $\boldsymbol{I}$, inverse-gamma; $\boldsymbol{U}$, uniform. 
For the shock processes, we find that four domestic disturbances (technology, preference, import cost-push, and risk premium) are either relatively or highly persistent. Regarding ten structural smoothed shocks, these volatilities exhibit relatively well the fluctuations in the Vietnamese and foreign economies over the period of 1999Q1-2017Q1. For example, based on Figure 19 in Appendix C, these ten structural smoothed variables fluctuate significantly throughout the special episodes, such as the early-2000 technology Y2K and 2008 global Recessions. In particular for the early-2000 technology-related crisis, there are substantial fluctuations in both domestic and foreign economy technology innovations. A similar pattern takes place in the case of shocks to external monetary and preference.

\section{Analysis}

In this section, we investigate the sources of the business cycle fluctuations in Vietnam. To do so, we use three different methods: impulse response function, forecast error variance decomposition, and historical decomposition.

\subsection{Impulse response functions}

This section presents the responses of six macroeconomic variables to several selected structural shocks. The other response to other structural disturbances can be found in the supplemental document. The dashed line implies the 90-percent probability band. Accordingly, there are, in general, are three striking features of the dynamic behavior of these variables toward ten structural disturbances as follows.

The first feature is that the dynamic responses of the six variables are all of the expected signs. For example, the demand-side disturbances, such as preference, risk premium, move domestic output, and CPI inflation, are in the same direction. Conversely, the supply-side disturbances, such as technology innovation, import cost-push, move domestic output, and CPI inflation, are in the opposite direction.

The second feature is that in most cases, the Vietnamese macroeconomic variables notably respond to the estimated shocks. However, two external-sector related disturbances, the term of trade and foreign technology shocks, cause a very mild change in macroeconomic fluctuation in Vietnam.

The last feature is that no shock permanently influences the Vietnamese economy. Indeed, variables quickly go back to their steady-state level after the shock, except for domestic CPI inflation and interest rate. Regarding domestic CPI inflation, it gradually returns to its steady-state level due to the presence of the nominal friction, such as price rigidity in the underlying model. Meanwhile, the persistent changes in the domestic interest rate are explained by the highly estimated value for a parameter associated with smoothing in the policy rule $\left(\psi_{i}=0.89\right)$. In fact, the actual data on this variable shows a persistent pattern as well (see Figure 5).

The dynamic behavior of each variable toward each structural shock is presented below. 


\subsubsection{Shock to domesic monetary policy}

Figure 7 shows how six macroeconomic variables respond to an estimated monetary policy shock (contractionary monetary policy). Accordingly, it translates into a rise of 40 basis points (bps) in the domestic interest rate. Meanwhile, output growth, CPI inflation, and term of trade fall. Moreover, Figure 7 presents a stronger response in domestic output growth than domestic CPI inflation. As an example, the estimated monetary policy disturbance causes an over-60-basis-point decline in domestic output growth, but a slightly over-40-basis-point fall in domestic CPI inflation. Hence, during the period of anti-inflation, the SBV should implement a contractionary monetary policy with caution. Via the UIP, on the other hand, the domestic contractionary monetary policy causes the appreciations of both real and nominal exchange rate $(U S D / V N D)$. Indeed, the nominal and real exchange rates appreciate around 150 bps, and 100 bps, respectively.
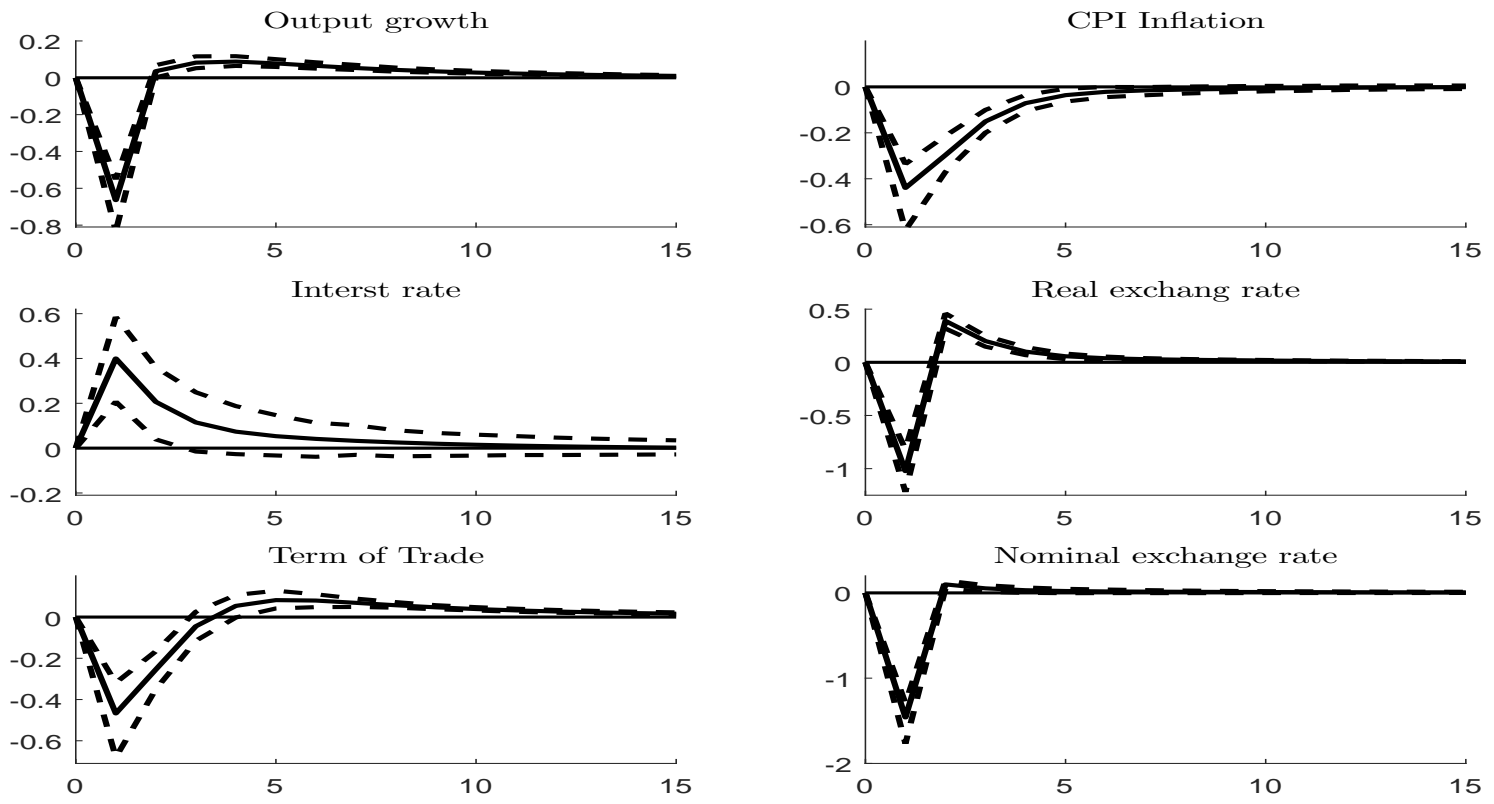

Figure 7: Shock to the domesic contractionary monetary policy

\subsubsection{Shock to domesic technology}

Figure 8 presents the shock to domestic stationary productivity technology. As a supply-side disturbance, it leads to an expansion of 40 bps in output growth, but a decline of approximately $100 \mathrm{bps}$ in the domestic CPI inflation. On the other hand, there is an increase of over 100 bps in terms of trade. Intuitively, because of a rise in productivity, there is a fall in the real marginal cost, which in turn lowers the domestic-goods price $P_{H, t}$. As a result, domestic CPI inflation declines, but the term of trade rises. Along with this, the real exchange rate depreciates. Meanwhile, via the policy rule, a fall in domestic CPI inflation translates to a decrease of around $50 \mathrm{bps}$ in the domestic interest rate. Finally, via the UIP, the nominal exchange rate appreciates. 

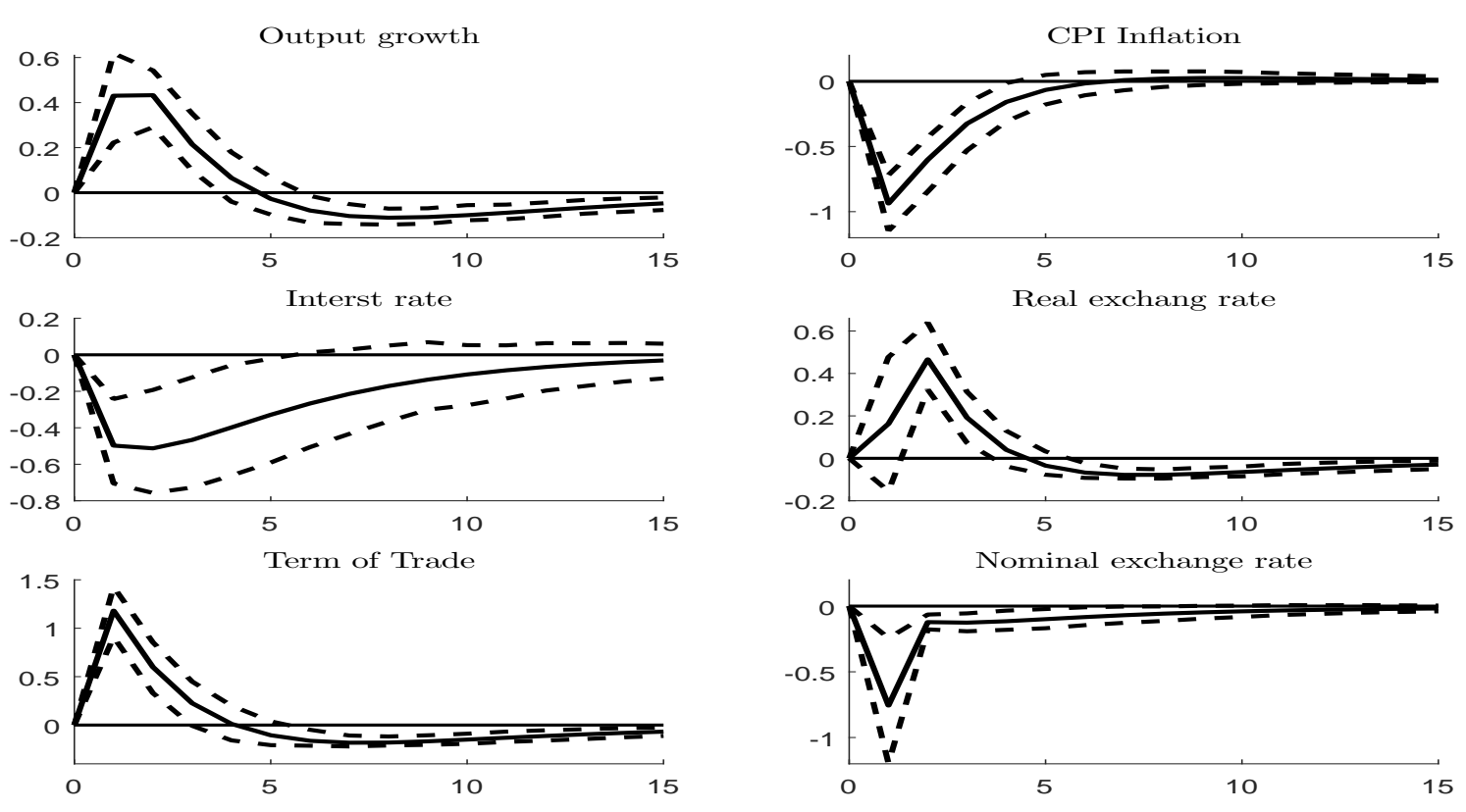

Figure 8: Positive shock to domesic technology

\subsubsection{Shock to domestic preference}

Figure 9 presents the shocks to domestic preference. Indeed, a positive shock to preference can be interpreted as an increase in domestic consumption demand. Thus, it leads to an expansion of over $100 \mathrm{bps}$ in domestic output growth. On the other hand, as a domestic demand-side disturbance, it causes higher domestic CPI inflation. Indeed, domestic CPI inflation rises by 10 bps. However, the response of domestic CPI inflation is negligible. This is because its probability band includes zero. This disappointing finding will be discussed further in Section 6.2.2.

Via the policy rule, on the other hand, the increases in domestic output growth and CPI inflation generate rises in the domestic interest rate. Indeed, it peaks at around 75bps after three quarters. Meanwhile, via the UIP, this rise in the domestic interest rate leads to the appreciation of the nominal exchange rate (over $50 \mathrm{bps}$ ). On the other hand, due to the higher price of domestic goods $P_{H, t}$, the term of trade declines. Thus, the real exchange rate appreciates by over 50 bps. 

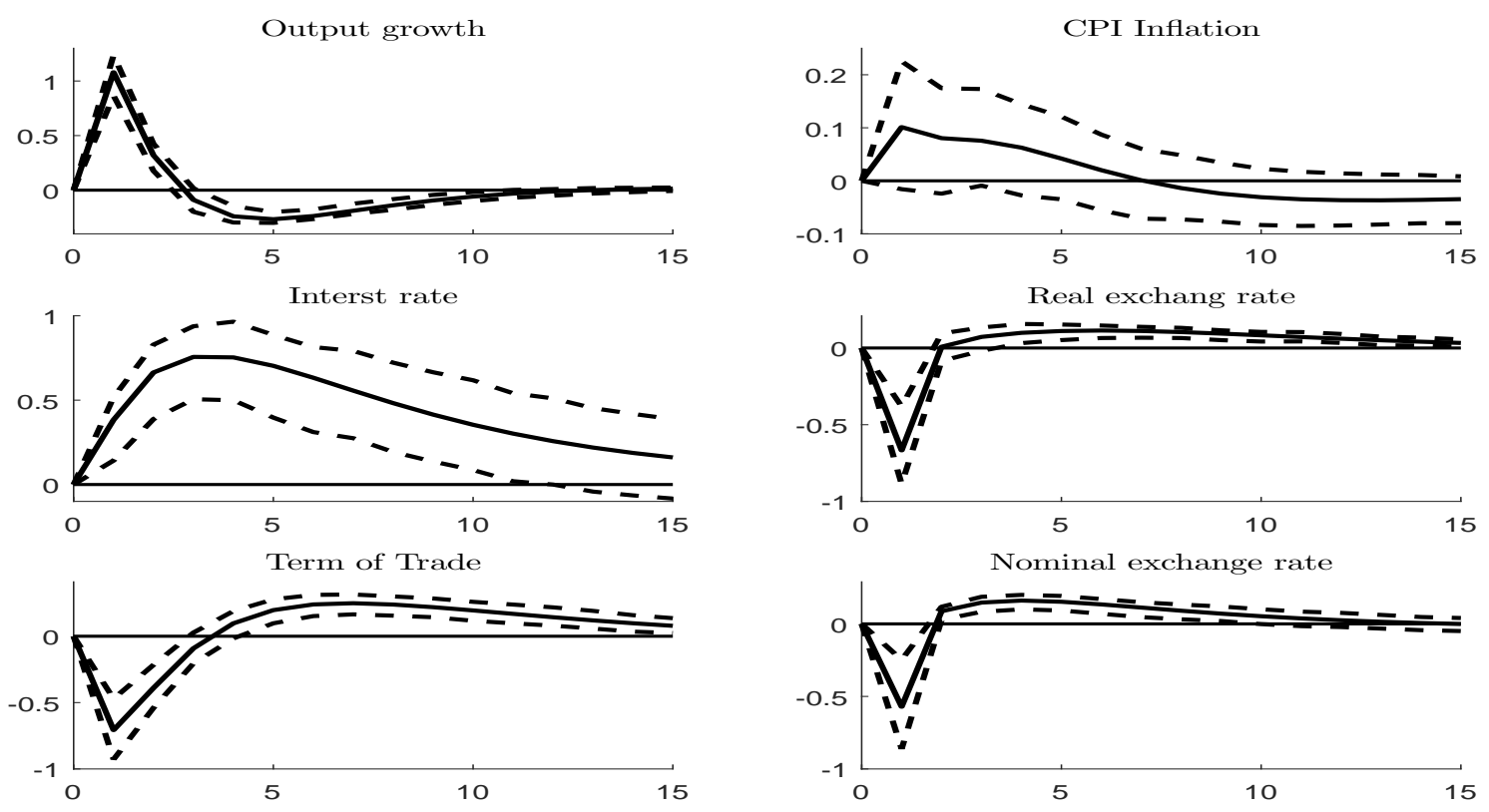

Figure 9: Positive shock to domesic preference

\subsubsection{Shock to import cost-push}

Figure 10 presents the positive shock to import cost-push. This adverse shock firstly increases the imported-goods price inflation, $\pi_{F, t}$. It then translates to into an over-50basis-point increase in domestic CPI inflation via the aggregate price. Besides, a rise in the imported price inflation, $\pi_{F, t}$, causes the term of trade to increase by almost $100 \mathrm{bps}$. On the other hand, via the link with the LOOP gap, the real exchange rates witness the appreciation of 100 bps. Meanwhile, the rise in domestic CPI inflation translates to an increase in the domestic interest rate via the policy rule. It, in turn, leads to the appreciation of the nominal exchange rate. Thus, these appreciations of both the nominal and real exchange rates decrease the domestic output growth. 

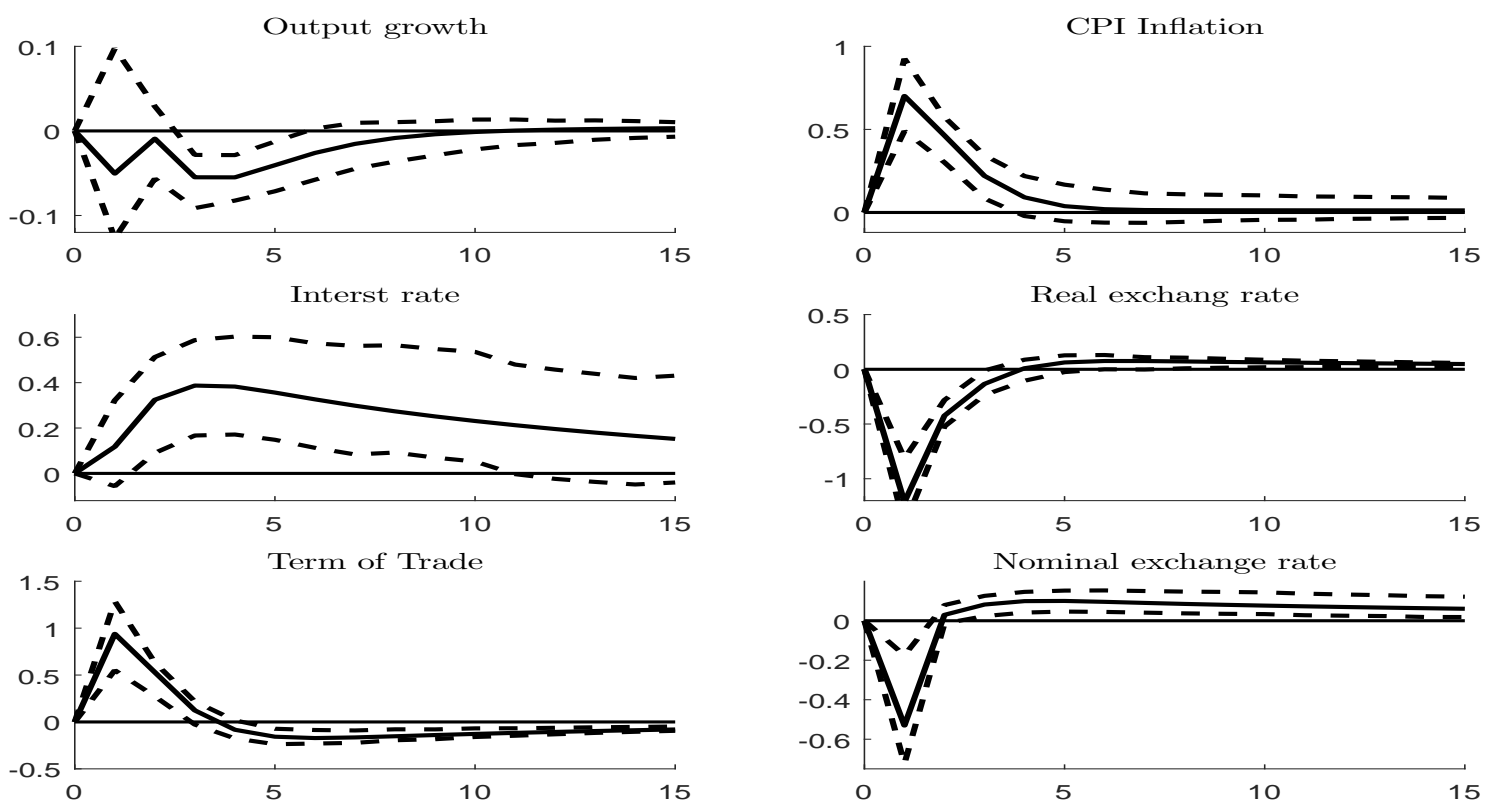

Figure 10: Positive shock to import cost push

\subsubsection{Shock to risk premium}

An estimated shock to risk premium appreciates both nominal and real exchange rates by approximately $150 \mathrm{bps}$, and $120 \mathrm{bps}$, respectively. The appreciation of the exchange rate decreases the price of imported goods $\pi_{F, t}$. As a result, there is an increase in imports, which worsen the trade balance and domestic output growth (40 bps). On the other hand, the fall in $\pi_{F, t}$ results in a decline of around $60 \mathrm{bps}$ in terms of trade and $40 \mathrm{bps}$ in domestic CPI inflation. Finally, via the policy rule, all declines in domestic CPI inflation, output growth, and nominal exchange rate generate a fall of 100 bps in domestic interest rate.
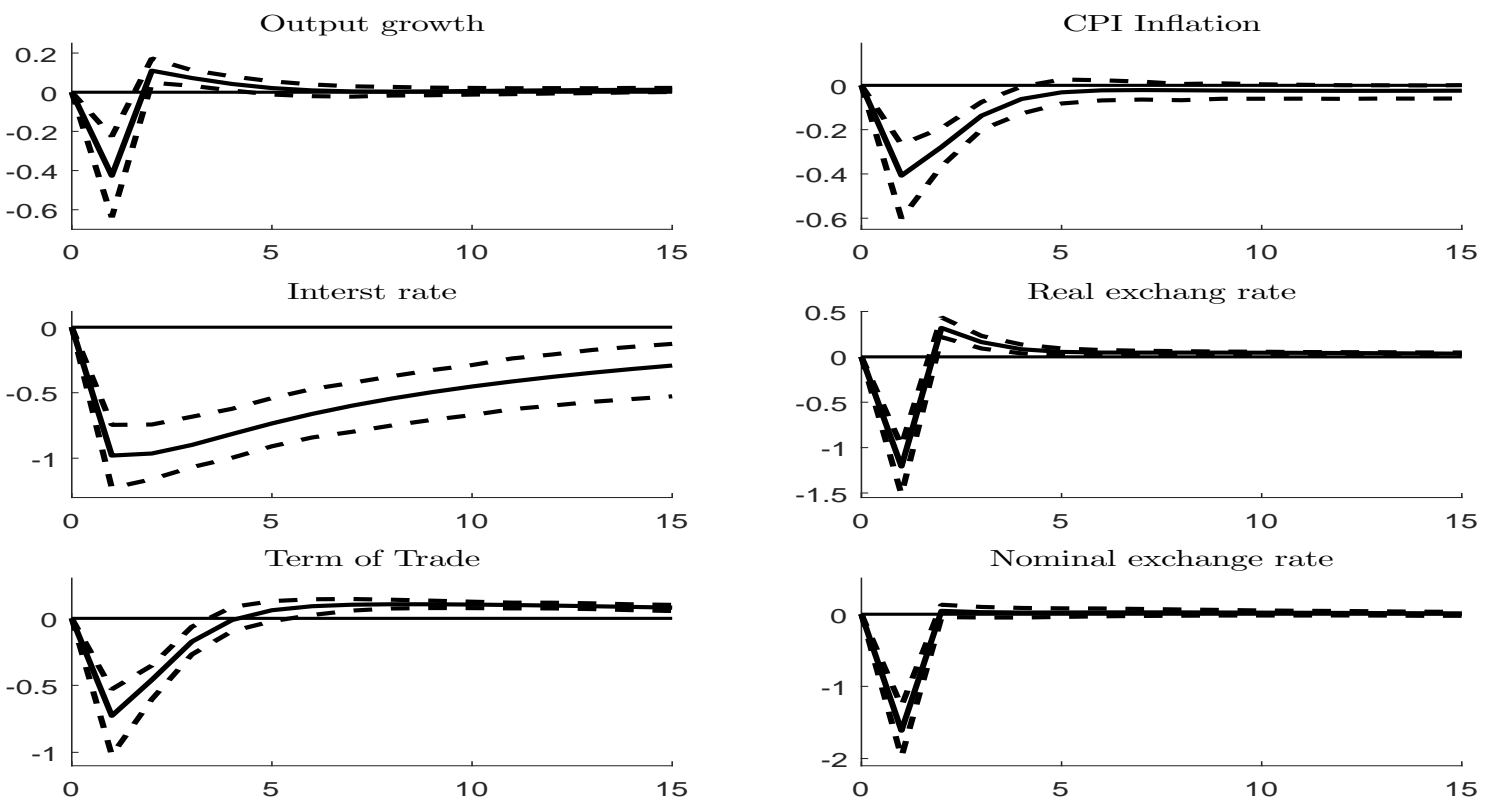

Figure 11: Positive shock to risk premium 
Furthermore, we examine the short-run exchange-rate pass-through (ERPT) for Vietnam. We do so by using the shock to risk premium. This is because this shock can be viewed as an autonomous change in the expectation about the future exchange rate (see the equation (3.9.9p). In addition, the ERPT measures how domestic CPI responds to the changes in the nominal exchange rate, which is $100 * \Delta$ price $_{t} / \Delta e_{t}$. Thus, the ERPR also implies the transmission of the international spillovers on the Vietnamese economy through the exchange rate channel.

Based on the impulse response function in Figure 11, the short-run incomplete ERPT in Vietnam is $100 * \frac{\Delta \pi_{t}}{\Delta e_{t}}=100 * \frac{40 b p s}{150 b p s}=26.67 \%$ after 3 months. It is worth noting that the estimated ERPT is not directly comparable because of differences in samples and the underlying assumptions. However, we argue that the ERPT of $26.67 \%$ is relatively higher in Vietnam in comparison to other emerging and developed countries. More specifically, the greater and more-rapid EPRT in Vietnam compared to industrialized countries reflects well the unique feature of developing countries (see Frankel et al. (2012)).

Such rapid and high ERPT in Vietnam can be explained as follows. Accordingly, in our model specification, the incomplete ERPT is influenced by two channels: marginal cost and import price stickiness. In terms of marginal cost channel, the changes in the exchange rate pass through domestic price via term of trade, $s_{t}$. The magnitude of this effect is governed by a highly estimated degree of openness, $\alpha=0.56$ (see the equation (3.9.6) and Table 1). On the other hand, the second channel related to imported price stickiness, $\theta_{F}$, reveals a relatively frequent change in price in Vietnam, such as every six months.

\subsubsection{Shock to the term of trade}

This section is interesting since we examine a crucial issue about the role of the term of trade shock to aggregate activities. Indeed, the current literature shows mixed findings on this issue. For example, the conventional view argued that the effects of the the term of trade shock on aggregate activities account for $30 \%$ (Mendoza (1995), Kose (2002)). However, based on the estimated SVAR and MXN ${ }^{3}$ models, a recent striking study of Schmitt-Grohé and Uribe (2018) argued that this shock displays a modest role of $10 \%$ in driving aggregate activities in 30 poor and emerging nations.

Figure 12 presents the positive shock to the term of trade. Accordingly, an estimated shock to the term of trade results in increases in CPI inflation and interest rate. On the other hand, it leads to an expansion in output. However, these responses of output to the term-of-trade shock are negligible. As an example, its $90 \%$ probability band includes zero.

\footnotetext{
${ }^{2}$ The third channel is mark-up. In particular, in the imperfectly competitive market, firms can charge a markup on cost. Furthermore, it is worth noting that this channel will influence the ERPT only if the assumption about time-varying mark-up is made (see Aron et al. (2013)). However, there is no mark-up in this underlying model. Thus, in our model specification, the incomplete ERPT is mainly influenced by two sources: marginal cost and import price stickiness.

${ }^{3}$ The MXN model includes an importable sector (the $\mathrm{m}$ sector), an exportable sector (the $\mathrm{x}$ sector), and a nontradable sector (the $\mathrm{n}$ sector). The detailed MXN model can be referred to Schmitt-Grohé and Uribe (2018).
} 
Thus, the terms-of-trade shock is not the primary source of business cycle fluctuations in Vietnam. This finding is identical to a recent striking study by Schmitt-Grohé and Uribe (2018). In particular, these authors argued: "On average across countries a positive terms-of-trade shock causes an improvement in the trade balance and an expansion in output, this improvement is statistically insignificant (as measured by the error bands including 0) in 18 countries for the trade balance and in 24 countries for output in our panel of 38 countries. Similar results obtain for the other variables included in the SVAR. These findings are a prelude to the main result of this section, namely that SVAR evidence suggests that terms-of-trade shocks are not a major source of fluctuations in emerging and developing countries during the sample period considered."
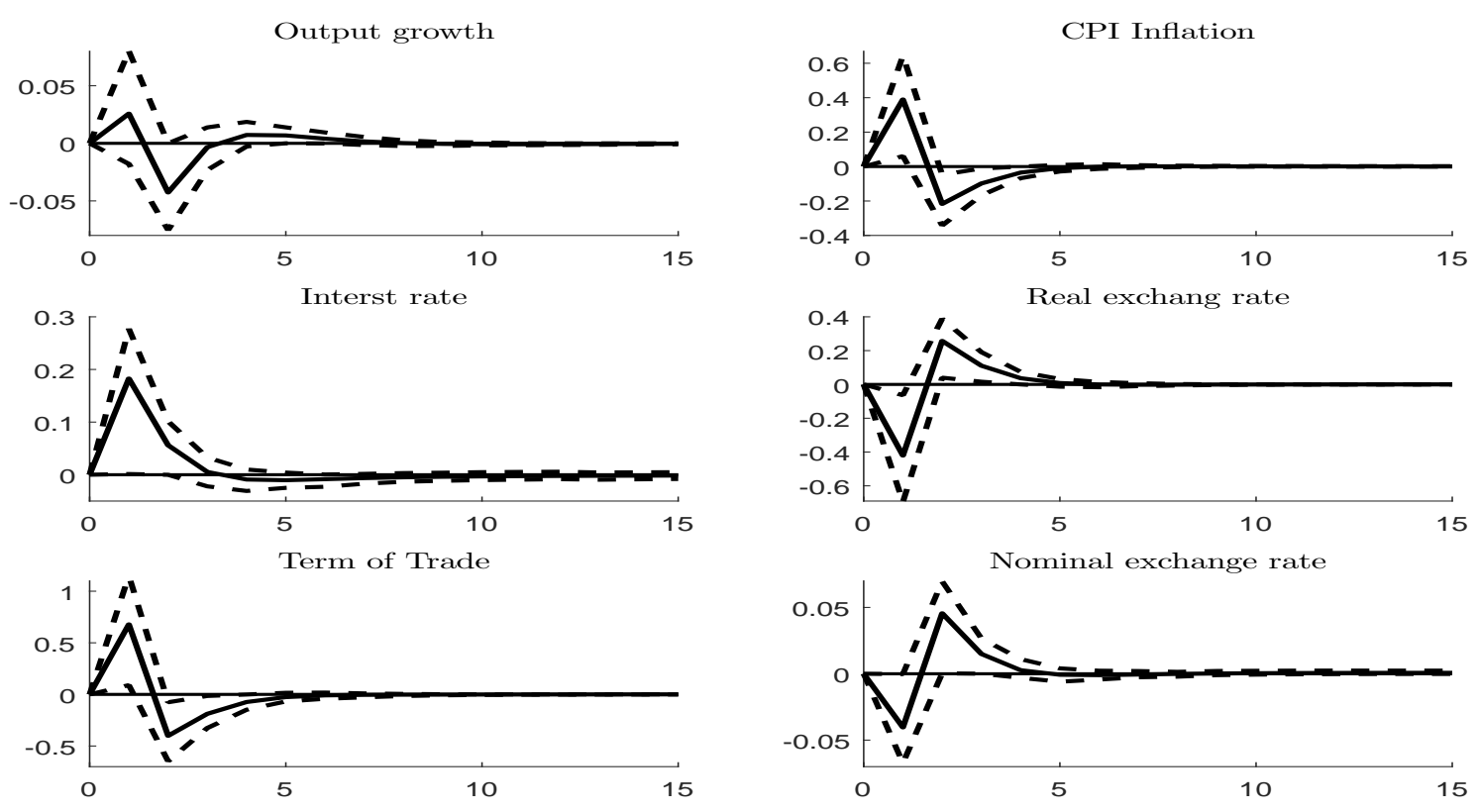

Figure 12: Positive shock to Term of Trade

\subsection{Forecast Error Variance decomposition}

We go further to investigate the business cycle fluctuations in Vietnam with the help of the forecast error variance decomposition (FEVD) technique. Accordingly, Table 2 presents how each structural shock contributes to the variations in six Vietnamese macroeconomic variables: output, inflation, interest rate, real and nominal exchange rates, and term of trade.

Overall, the fluctuations in all cases of the nominal variables, such as domestic CPI inflation, interest rate, exchange rates and the term of trade, are mainly explained by the external-sector related disturbances. This finding is not surprising at this finding since Vietnam is one of the most open economies in the world. However, the changes in the real aggregate variable, such as domestic output growth, are largely driven by its domestic shock, in particular, domestic consumption demand (domestic preference shock). Similar to the IRF-based analysis, on the other hand, the FEVD technique also reveals a very mild role of a shock to the term of trade. 
Table 2: Forecast Error Variance decomposition

\begin{tabular}{|c|c|c|c|c|c|c|c|c|c|c|}
\hline \multirow{2}{*}{ Quarters } & \multicolumn{4}{|c|}{ Foreign shocks } & \multicolumn{6}{|c|}{ Domestic shocks } \\
\hline & $\sigma_{i *}$ & $\sigma_{a *}$ & $\sigma_{c p *}$ & $\sigma_{z *}$ & $\sigma_{z}$ & $\sigma_{g}$ & $\sigma_{c p}$ & $\sigma_{r p}$ & $\sigma_{t o t}$ & $\sigma_{m}$ \\
\hline & \multicolumn{10}{|c|}{ Domestic output growth } \\
\hline 01 & 0.02 & 7.52 & 0.23 & 0.00 & 8.64 & 54.39 & 0.12 & 8.48 & 0.03 & 20.57 \\
\hline 04 & 0.34 & 6.97 & 0.31 & 0.00 & 16.10 & 50.78 & 0.33 & 7.66 & 0.10 & 17.40 \\
\hline 08 & 0.35 & 6.99 & 0.35 & 0.00 & 15.75 & 52.67 & 0.39 & 7.01 & 0.09 & 16.40 \\
\hline 12 & 0.35 & 7.01 & 0.35 & 0.00 & 16.66 & 52.10 & 0.39 & 6.88 & 0.09 & 16.18 \\
\hline 20 & 0.35 & 7.02 & 0.35 & 0.00 & 17.03 & 51.80 & 0.39 & 6.87 & 0.09 & 16.10 \\
\hline \multirow[t]{2}{*}{40} & 0.35 & 7.02 & 0.36 & 0.00 & 17.04 & 51.77 & 0.40 & 6.89 & 0.09 & 16.08 \\
\hline & \multicolumn{10}{|c|}{ Domestic CPI inflation } \\
\hline 01 & 0.14 & 1.67 & 2.45 & 0.00 & 44.46 & 0.52 & 24.89 & 8.41 & 7.68 & 9.79 \\
\hline 04 & 0.18 & 3.18 & 4.41 & 0.00 & 42.92 & 0.82 & 23.90 & 8.34 & 6.57 & 9.68 \\
\hline 08 & 0.24 & 3.31 & 4.49 & 0.00 & 42.75 & 0.89 & 23.79 & 8.35 & 6.52 & 9.67 \\
\hline 12 & 0.24 & 3.30 & 4.56 & 0.00 & 42.65 & 1.01 & 23.72 & 8.39 & 6.49 & 9.64 \\
\hline 20 & 0.24 & 3.29 & 4.55 & 0.00 & 42.48 & 1.26 & 23.65 & 8.48 & 6.46 & 9.60 \\
\hline \multirow[t]{2}{*}{40} & 0.24 & 3.29 & 4.53 & 0.00 & 42.34 & 1.38 & 23.63 & 8.58 & 6.44 & 9.56 \\
\hline & \multicolumn{10}{|c|}{ Domestic interest rate } \\
\hline 01 & 2.73 & 6.02 & 0.82 & 0.00 & 14.34 & 8.51 & 0.80 & 55.58 & 1.93 & 9.26 \\
\hline 04 & 0.97 & 11.26 & 2.59 & 0.00 & 11.36 & 22.13 & 5.32 & 43.06 & 0.47 & 2.83 \\
\hline 08 & 0.62 & 12.50 & 2.32 & 0.00 & 9.30 & 25.79 & 6.62 & 40.69 & 0.30 & 1.85 \\
\hline 12 & 0.55 & 12.40 & 2.07 & 0.00 & 8.49 & 25.98 & 7.27 & 41.34 & 0.26 & 1.64 \\
\hline 20 & 0.51 & 12.03 & 1.93 & 0.00 & 7.98 & 25.43 & 7.83 & 42.51 & 0.25 & 1.53 \\
\hline \multirow[t]{2}{*}{40} & 0.50 & 11.84 & 1.90 & 0.00 & 7.85 & 25.19 & 7.99 & 42.99 & 0.24 & 1.51 \\
\hline & \multicolumn{10}{|c|}{ Real exchange rate } \\
\hline 01 & 2.03 & 1.10 & 1.94 & 0.00 & 0.54 & 9.13 & 30.20 & 29.94 & 3.63 & 21.48 \\
\hline 04 & 2.36 & 1.11 & 2.66 & 0.00 & 4.81 & 7.84 & 28.42 & 27.16 & 4.38 & 21.26 \\
\hline 08 & 2.31 & 1.24 & 2.96 & 0.00 & 5.00 & 8.47 & 28.14 & 26.72 & 4.28 & 20.89 \\
\hline 12 & 2.28 & 1.33 & 3.01 & 0.00 & 5.18 & 8.76 & 28.04 & 26.52 & 4.23 & 20.65 \\
\hline 20 & 2.27 & 1.37 & 3.00 & 0.00 & 5.24 & 8.81 & 28.12 & 26.48 & 4.20 & 20.52 \\
\hline \multirow[t]{2}{*}{40} & 2.26 & 1.37 & 3.00 & 0.00 & 5.23 & 8.81 & 28.23 & 26.45 & 4.19 & 20.47 \\
\hline & \multicolumn{10}{|c|}{ Nominal exchange rate } \\
\hline 01 & 4.28 & 0.17 & 0.05 & 0.00 & 9.23 & 5.26 & 4.54 & 42.04 & 0.03 & 34.40 \\
\hline 04 & 4.20 & 0.20 & 0.13 & 0.00 & 9.72 & 6.01 & 4.72 & 41.14 & 0.06 & 33.83 \\
\hline 08 & 4.11 & 0.27 & 0.19 & 0.00 & 9.90 & 6.84 & 5.15 & 40.33 & 0.06 & 33.15 \\
\hline 12 & 4.08 & 0.29 & 0.20 & 0.00 & 9.92 & 6.95 & 5.47 & 40.09 & 0.06 & 32.94 \\
\hline 20 & 4.06 & 0.29 & 0.21 & 0.00 & 9.91 & 6.93 & 5.84 & 39.91 & 0.06 & 32.79 \\
\hline \multirow[t]{2}{*}{40} & 4.04 & 0.30 & 0.21 & 0.00 & 9.87 & 7.03 & 6.16 & 39.71 & 0.06 & 32.62 \\
\hline & \multicolumn{10}{|c|}{ Term of trade } \\
\hline 01 & 0.47 & 1.04 & 2.62 & 0.00 & 33.57 & 12.03 & 21.21 & 12.73 & 11.07 & 5.26 \\
\hline 04 & 0.42 & 1.90 & 5.20 & 0.00 & 31.04 & 11.51 & 20.35 & 13.24 & 11.38 & 4.95 \\
\hline 08 & 0.43 & 2.04 & 5.27 & 0.00 & 30.07 & 13.93 & 20.30 & 12.65 & 10.44 & 4.87 \\
\hline 12 & 0.41 & 2.35 & 5.39 & 0.00 & 29.57 & 15.15 & 20.06 & 12.54 & 9.85 & 4.68 \\
\hline 20 & 0.40 & 2.51 & 5.34 & 0.00 & 29.25 & 15.31 & 20.16 & 12.85 & 9.60 & 4.58 \\
\hline 40 & 0.39 & 2.52 & 5.32 & 0.00 & 29.16 & 15.33 & 20.18 & 12.97 & 9.56 & 4.57 \\
\hline
\end{tabular}

Note: Values are measured in percent. Variables with the symbol star (*) belong to foreign economy. 


\subsubsection{Output growth}

Table 2 shows that variations in output growth in Vietnam are mainly led by domestic preference shock, $\sigma_{g}$. Accordingly, it accounts for more than half in both the short and long run. This finding is identical to the literature on the model with nominal rigidities in that the demand side has tended to play the dominant role (see Gali (2002)).

On the other hand, stationary technology shock contributes less than $18 \%$. Even though there is no observed data on employment, this relatively limited contribution would imply the opposite movements in output and employment in response to an increase in stationary technology shock in Vietnam. Indeed, this finding and its implication are identical to the standard literature on the NK-DSGE model (see Gali (2002), Smets and Wouters (2003), Adolfson et al. (2007)). For example, Gali (2002) argued: "In a model with imperfect competition and sticky prices, a favorable technology shock is likely to induce a short-run decline in employment". Meanwhile, both Smets and Wouters (2003) and Adolfson et al. (2007) found that an increase in stationary technology shock raises output, whereas it decreases employment. In particular, Smets and Wouters (2003) argued: "The limited importance of productivity shocks (maximum 12\% of forecast error variance in output) confirms the conjecture made in Gali (2000) that the negative correlation between output and employment in response to a productivity shock raises serious doubts about the quantitative significance of productivity shocks as a source of aggregate fluctuations".

The exception for the first three months is that the role of monetary policy accounts for less than $20 \%$ in explaining the variations in the Vietnamese output growth. On the other hand, all foreign shocks account for a proportion of around $15 \%$. This finding is a disappointment since the Vietnamese economy strongly depends on international trade and financial linkages. It implies misspecification in the SOE-NK-DSGE model that has been widely accepted in the current literature (Justiniano and Preston (2010a), Engel (2014), Gourinchas and Rey (2014)).

\subsubsection{CPI inflation}

The FEVD technique reveals that the fluctuations in the domestic CPI inflation in Vietnam are mainly driven by stationary technology disturbance (see Table 2). Accordingly, it accounts for over $40 \%$.

Meanwhile, policy shock accounts for less than $10 \%$. On the other hand, there is concrete evidence in favor of a sizeable influence of the external sector on the CPI inflation in Vietnam. More specifically, the shock to import cost-push, $\sigma_{c p}$, accounts for approximately one fourth. Therefore, all of seven foreign shocks are notably responsible for around 45 percent of the volatilities of the domestic CPI inflation in Vietnam.

On the other hand, the contribution of domestic preference shock accounts for a negligible percentage. Meanwhile, as analyzed before, the response of this variable to domestic preference shock is also the insignificantly statistical response. This fact can be explained as follows. The effect of domestic preference shock on the domestic CPI inflation is transmitted via several channels in between. At first, it influences domestic consumption 
via the New Keynesian IS curve. This impact is then transmitted to the domestic real marginal cost, $m c_{t}$. Through this channel, the domestic price inflation, $\pi_{H}$, will be impacted. Finally, this shock arrives at the domestic CPI inflation via the aggregate price. It is worthwhile noting that the magnitude of the effect of this shock on the domestic CPI inflation is only governed by the coefficient associated with the domestic real marginal cost, $m c_{t}$, in the domestic firm's hydrid NKPC 4 . Particularly, it is $\frac{\left(1-\theta_{H}\right)\left(1-\beta \theta_{H}\right)}{\theta_{H}\left(1+\beta \theta_{H}\right)}$. Therefore, the magnitude of the effect of this shock on the domestic CPI inflation will be either amplified or dampened by this coefficient. Indeed, the estimation leads to a small valu $\complement^{5}$ of 0.013. Consequently, there is a negligible contribution of the domestic preference shock to the CPI inflation as mentioned before.

\subsubsection{Domestic interest rate}

It is not surprising that

The shock to risk premium is the primary source in driving the domestic interest rate in Vietnam. Accordingly, this shock accounts for over half for the first quarter and over $40 \%$ for higher horizons.

The finding on the most significant contribution of the risk premium to the variations in the domestic interest rate can be explained by the strong connection between these two variables. More specifically, the changes in domestic interest rate are closely related to risk premium via two channels: uncovered interest rate parity and policy rule (see the equations (3.9.9) and (3.9.11)). As an example, an estimated value for a parameter associated with the exchange rate, $\psi_{\Delta e}$, in the policy is 0.81 , which is high in magnitude.

On the other hand, the domestic shock, such as the domestic preference, $\sigma_{g}$, is the second-largest source of driving interest rate. An exception to the first quarter, for example is that preference shock accounts for around one fourth.

\subsubsection{The nominal and real exchange rates}

It is not surprising that the external-sector related shocks largely explain the fluctuations in these two external-sector linked variables. Regarding the real exchange rate, for example, it measures the relative ratio of foreign goods price in terms of local currency (VND) to domestic goods price (see the equation (3.9.4)). Thus, the shocks to import cost-push, $\sigma_{c p}$, and risk premium, $\sigma_{r p}$, are dominant sources of driving this variable. Notably, they share an approximately equal role of $28 \%$, and $26 \%$ on the average, respectively. Meanwhile, a domestic disturbance, such as domestic monetary policy, accounts for slightly over $20 \%$. On the other hand, related to nominal exchange rate, risk premium $\left(\sigma_{r p}\right)$, is the dominant source which is followed by domestic monetary policy.

\footnotetext{
4 The effect of preference shock on domestic consumption is governed by parameter, $\frac{1-h}{\sigma}$ (see the NKIS curve (3.9.1) $)$. This effect will then translate into the domestic real marginal cost. The inverse parameter then governs it, $\frac{\sigma}{1-h}$. Therefore, the effect of domestic preference shock on domestic price inflation and CPI inflation is governed by only parameter, $\frac{\left(1-\theta_{H}\right)\left(1-\beta \theta_{H}\right)}{\theta_{H}\left(1+\beta \theta_{H}\right)}$.

5 Mathematically, it is $\frac{\left(1-\theta_{H}\right)\left(1-\beta \theta_{H}\right)}{\theta_{H}\left(1+\beta \theta_{H}\right)}=\frac{(1-0.858)(1-0.99 * 0.858)}{0.858 *(1+0.99 * 0.858)}=\frac{0.021}{1.587}=0.013$
} 
Accordingly, they account for around $40 \%$, and $33 \%$, respectively.

\subsubsection{Term of trade}

Table 2 shows that stationary technology disturbance plays the primary role in driving the changes in the term of trade. Indeed, it accounts for around $30 \%$. On the other hand, the import cost-push disturbance is the second-largest source (around 20\%). Meanwhile, two shocks to domestic preference and risk premium share an approximately equal role of over $12 \%$. Regarding the role of the term of trade shock, it is negligible (around $10 \%$ ). However, all seven foreign shocks make a notable contribution of around $55 \%$, whereas domestic monetary policy shock has an insignificant role.

\subsection{Historical decomposition}

This section finds the sources that drove the output growth and CPI inflation in Vietnam throughout the period 1999Q1 - 2017Q1. Thus, the historical decomposition technique is used. Figures $13-14$ show how each structural shock influences the fluctuations in these two Vietnamese macroeconomic variables. Accordingly, the black line presents the deviation of the smoothed value of the corresponding macroeconomic variable from its steady-state level.

\subsubsection{Output Growth}

Figure 13 presents the contribution of each structural shock to the output fluctuations for the period 1999Q1 - 2017Q1. In general, in most of the episodes, the variations in the Vietnamese output growth rate are associated with the demand-side disturbance (preference shock and risk premium).

The first episode is the period after the 1997-Asian crisis. Accordingly, there was a fall in the Vietnamese output growth. Figure 13 reveals two main factors associated with this decline. The first one, which is the primary source, is the significant decline in domestic consumption demand (negative preference shock). The second one is the negative shock to the risk premium. This shock would imply the appreciation of the nominal exchange rate in the second half of 1999 . 


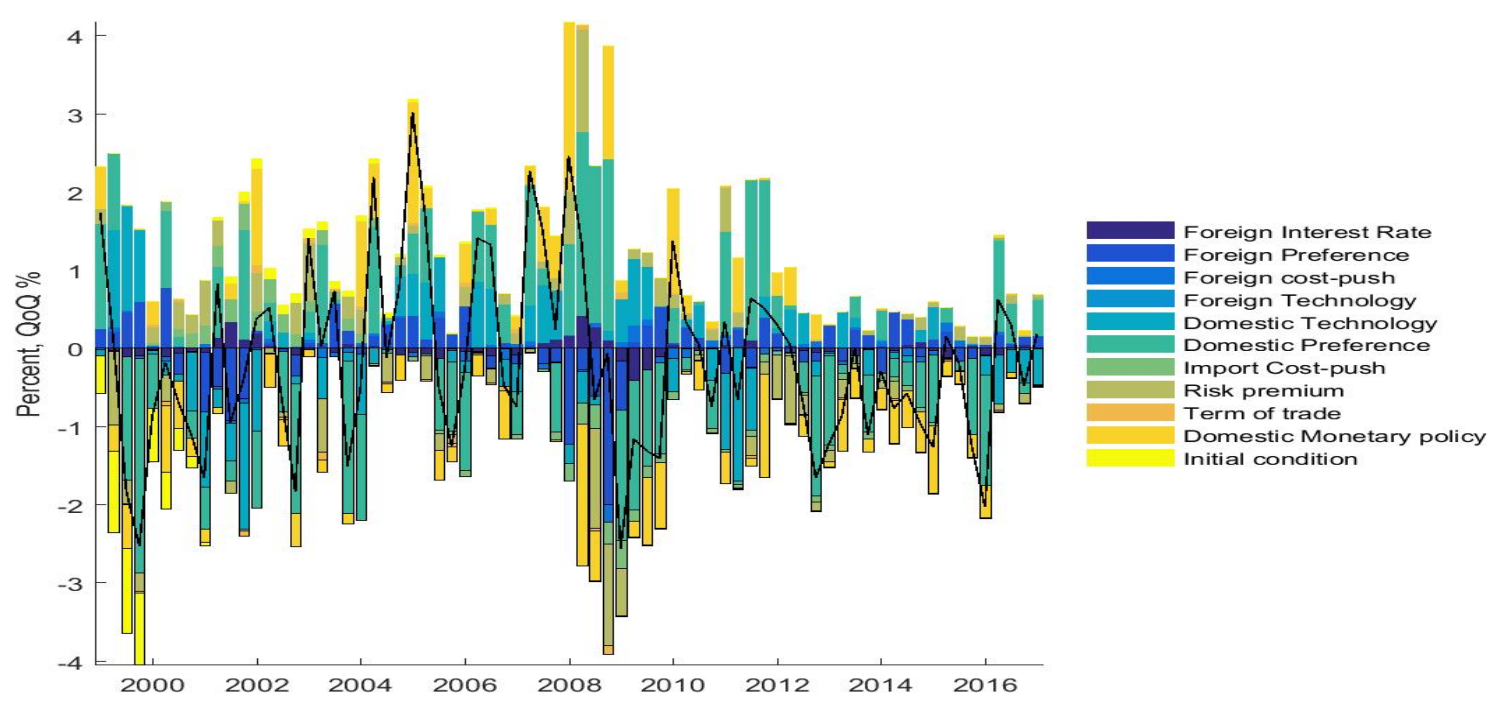

The second episode is the period of the early 2000s. In particular, the Vietnamese output growth recovers. According to Figure 13 , these economic recoveries are associated with the positive shock to the risk premium. Indeed, this shock presents the SBV's devaluation of VND relative to the USD. On the other hand, Figure 13 reveals three adverse shocks limiting the speed of the economic recovery. The first adverse one is domestic contractionary monetary policy. For example, the SBV raised its quarterly policy interest rate by 60 basis points in late 2000. Besides, this central bank made a considerable decrease in annual broad money growth. Regarding the two remaining adverse shocks, there are declines in foreign consumption demand and domestic stationary technology disturbances. These two adverse shocks might be linked with the early 2000 technology-related Recession, known as the Y2K crisis.

The third episode is the period of the economic boom of 2003 - 2007. Based on Figure 13. two main factors lead to the economic boom. The first one is the positive shock to the domestic monetary policy. For example, the SBV had pursued the expansionary monetary policy. Accordingly, this central bank held its quarterly policy interest rate at a stable level of around $5 \%$. Indeed, this level was the lowest one over the period of 1999Q1-2017Q1. Additionally, this central bank increased its annual broad money growth by over $30 \%$ per year, especially with the peak of approximately $50 \%$ in 2007 . Related to the second factor, domestic consumption expanded in most episodes. The expansionary monetary policy would cause these increases in domestic consumption. On the other hand, over this period, there is an insignificant contribution of the risk premium shock to the Vietnamese output growth. This fact might be explained by the relatively stable fluctuation in the nominal exchange rate before the global crisis.

The fourth episode is the global financial crisis. The global financial crisis took place 
in the US in 2007. However, it started to hit the Vietnamese economy in 2008. Figure 13 presents two dominant factors associated with a fall in output growth during the global financial crisis. The first one is the declines in foreign consumption. The second factor is the domestic contractionary monetary policy. Indeed, because of the pressure of high inflation in 2008, the SBV tightened its monetary policy. As a result, there were increases in the quarterly policy interest rate.

The last episode is the period after the global crisis. In Figure 13, there are two primary sources of driving output growth. The first one is a negative shock to monetary policy. The second one is an adverse shock to domestic consumption. These two adverse shocks would be linked to the monetary policy tightening over $2011-2012$ due to the two-digit inflation.

\subsubsection{CPI Inflation}

Figure 14 demonstrates the contribution of each structural shock to the domestic inflation fluctuations for the period 1999Q1 - 2017Q1. Overall, the variations in the Vietnamese CPI inflation is mainly influenced by import cost-push and monetary policy shocks.

Over the period of 1999 - 2003, Vietnam suffered from low inflation. According to Figure 14, two sources are associated with this low-inflation situation. The first one is the negative shock to import cost-push, which is a dominant source. Indeed, this negative shock would highly relate to the stable and lower-30-USD price of Brent Crude. On the other hand, the second source is a negative shock to monetary policy. This shock is associated with the monetary policy tightening. It is worth noting that, this monetary policy also limited the output growth as mentioned before. For example, the SBV raised its quarterly policy interest rate by 60 basis points in late 2000. Moreover, this central bank significantly declined its annual broad money growth rate in the early 2000s. 


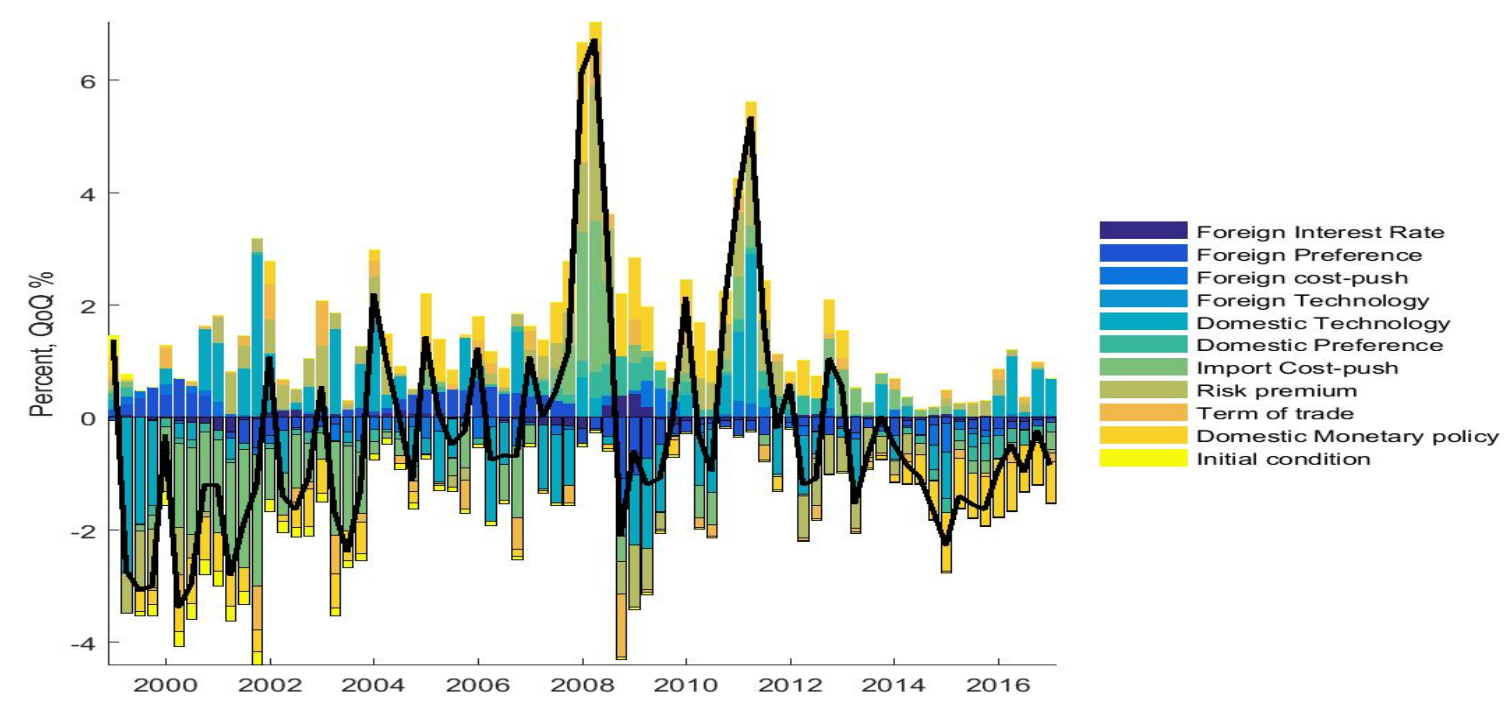

In the episode before the global crisis, the Vietnamese CPI had been increasing since 2004. It is worth noting that this episode belongs to the economic boom. Figure 14 shows that these increases in the CPI inflation have resulted from an expansionary monetary policy. More notably, this Figure reveals three primary sources associated with the twodigit inflation of $23.116 \%$ in 2008. Accordingly, the first one, which is a dominant source, is the import cost-push shock. This adverse shock to the import cost-push would be associated with the rocket in the world price of Brent crude over this stage. On the other hand, the second source is the risk premium shock, which is caused by the SBV's devaluations in early 2008. The third source is the adverse effect of expansionary monetary policy in the period of the economic boom. These three factors continue to cause a two-digit inflation of almost $19 \%$ in 2011.

Over the remaining periods, the CPI inflation in Vietnam declined. Accordingly, Figure 14 indicates two primary sources. The first one is the negative effect of the risk premium shock. This disturbance was linked to the high appreciation of the nominal exchange rate from the second half of 2011 to early 2012. On the other hand, the second source is the monetary policy tightening. Indeed, the SBV implemented this monetary policy over the period of $2011-2012$.

\section{Conclusion}

In this paper, we develop a SOE-NK-DSGE model for Vietnam. Accordingly, it is the first attempt. Indeed, the specification of this model closely follows the influential studies by Gali and Monacelli (2005), Monacelli (2005), and Justiniano and Preston (2010b) on the small open economy. On the other hand, the failures of the SOE-NK-DSGE model in 
explaining the effects of the international spillovers on a small open economy are widely admitted in the current literature. Thus, in order to reduce this problem, we specify a higher number of foreign shocks than its domestic counterpart. In particular, the model has seven foreign disturbances and three domestic shocks. To an extent, this specification coincides with the fact that Vietnam is one of the most open economies in the world. The model is then estimated using the Bayesian technique and the time series for Vietnam and the USA between 1999Q1 and 2017Q1. As a result, the estimated model fits observed data relatively well. On the other hand, with the help of the impulse response function, forecast error variance, and historical decomposition techniques, several findings on the business cycle fluctuations in this emerging economy are revealed.

The underlying theoretical model of the SOE-NK-DSGE model is a small-sized type. For further research, this model can be enriched by incorporating other features as follows. As an example, in this paper, the domestic household directly supplies its labor to the domestic firm (see Figure 3). Therefore, there is no nominal friction of the wage stickiness. For further research, to introduce this friction, the model should adopt the assumption that the domestic household is unable to supply its labor directly to an intermediate goods firm. Instead of this, there is a labor-transforming firm. This firm aggregates a homogenous unit of labor and sells to intermediate goods at the wage $W_{H, t}$. On the other hand, this labor-transforming firm resets its wage according to the Calvo-style setting.

On the other, over the last decade, the structural model with financial friction has been one of growing interest. Thus, this small-sized model can include this friction by introducing a banking sector. Indeed, the domestic household holds a deposit at the bank. The bank, in turn, lends to the domestic intermediate goods firm. This borrowing is done to finance the intermediate goods firm's wage bill in advance (working capital channel as in the study by Adolfson et al. (2007)).

\section{References}

Adjemian, S., Bastani, H., Juillard, M., Karamé, F., Maih, J., Mihoubi, F., Perendia, G., Pfeifer, J., Ratto, M., and Villemot, S. (2011). DYNARE: Reference Manual, Version 4. Dynare Working Papers, 1, CEPREMAP.

Adolfson, M., Laseén, S., Lindé, J., and Villani, M. (2007). Bayesian estimation of an open economy DSGE model with incomplete pass-through. Journal of International Economics, 72 (2):481-511.

Adolfson, M., Laséen, S., and Lindé, J. (2008). Empirical properties of closed-and openeconomy DSGE models of the Euro area. Macroeconomic Dynamics, 12(1):2-19.

Aguiar, M. and Gopinath, G. (2007). Emerging Market Business Cycles: The Cycle Is the Trend. Journal of Political Economy, 115(1):69-101. 
An, S. and Schorfheide, F. (2007). Bayesian Analysis of DSGE Models. Econometric Reviews, 26:113-172.

Aron, J., Macdonald, R., and Muellbauer, J. (2013). Exchange Rate Pass-Through in Developing and Emerging Markets: A Survey of Conceptual, Methodological and Policy Issues, and Selected Empirical Findings. The Journal of Development Studies, 50(1):101-143.

Benjamin, D. and Meza, F. (2009). Total Factor Productivity and Labor Reallocation: The Case of the Korean 1997 Crisis. The B.E. Journal of Macroeconomics, 9(1):Article 31.

Berg, Andrew, P. K. and Laxton, D. (2006a). A Practical Model-Based Approach to Monetary Policy Analysis: Overview. IMF Working Paper, WP/06/80.

Berg, Andrew, P. K. and Laxton, D. (2006b). Practical Model-Based Monetary Policy Analysis-A How-To Guide. IMF Working Paper, WP/06/81.

Boz, E., Daude, C., and Durdu, C. (2011). Emerging market business cycles: Learning about the trend. Journal of Monetary Economics, 58(6-8:616-631.

Boz, E., DURDU, C. B., and LI, N. (2015). Emerging Market Business Cycles: The Role of Labor Market Frictions. Journal of Money, Credit and Banking, 47(1):31-72.

Buncic, D. and Melecky, M. (2008). An Estimated New Keynesian Policy Model for Australia. Economic Record, 84(264):1-16.

Castillo, P., Montoro, C., and Tuesta, V. (2013). An Estimated Stochastic General Equilibrium Model with Partial Dollarization: A Bayesian Approach. Open Economies Review, 24(2):217-265.

Choi, J. and Hur, J. (2015). An examination of macroeconomic fluctuations in Korea exploiting a Markov-switching DSGE approach. Economic Modelling, 51:183-199.

Christiano, L. J., Eichenbaum, M., and Evans, C. (2005). Nominal rigidities and the dynamic effects of a shock to monetary policy. Journal of Political Economy, 113 $(1): 1-45$.

Christiano, L. J., Trabandt, M., and Walentin, K. (2010). DSGE Models for Monetary Policy Analysis. Handbook of Monetary Economics, 3:285-367.

Dai, L., Minford, P., and Zhou, P. (2015). A DSGE model of China. Applied Economics, 47(59):6438-6460.

Dizioli, A. and Schmittmann, J. M. (2015). A Macro-Model Approach to Monetary Policy Analysis and Forecasting for Vietnam. IMF Working Paper, WP/15/273. 
Elekdag, S., Justiniano, A., and Tchakarov, I. (2005). An Estimated Small Open Economy Model of the Financial Accelerator. IMF Working Paper No. 05/44.

Elisa, P. and Padilla, I. (2011). Business cycles in a small open economy: The case of Hong Kong. DFAEII Working Papers 2011-07, University of the Basque Country.

Engel, C. (2014). Exchange Rates and Interest Parity. Handbook of International Economics, 4:453-522.

Frankel, J., Parsle, D., and Wei, S.-J. (2012). Slow pass-through around the world: A new import for developing countries? Open Economies Review, 23:213-251.

Fuhrer, J. C. (2000). Habit formation in consumption and its implications for monetarypolicy models. American Economic Review, 90(3):367-390.

Gabriel, V., Levine, P., and Yang, B. (2016). An Estimated DSGE Open Economy Model of the Indian Economy with Financial Frictions. Monetary Policy in India: A Modern Macroeconomic Perspective, pages 455-506.

Gali, J. (2002). New Perspectives on Monetary Policy, Inflation, and the Business Cycle. NBER Working Paper, No. 8767.

Gali, J. and Gertler, M. (1999). Inflation dynamics: A structural economic analysis. Journal of Monetary Economics, 44(2):195-222.

Gali, J. and Monacelli, T. (2005). Monetary policy and Exchange Rate volatility in a small open economy. The Review of Economic Studies, 72 (3):707-734.

Galí, J., Gertler, M., and López-Salido, J. D. (2005). Robustness of the estimates of the hybrid New Keynesian Phillips curve. Journal of Monetary Economics, 52(6):11071118.

Garcia, C. J., Restrepo, J. E., and Roger, S. (2011). How much should inflation targeters care about the exchange rate? Journal of International Money and Finance, 30:1590-1617.

García-Cicco, J., Pancrazi, R., and Uribe, M. (2010). Real Business Cycles in Emerging Countries? American Economic Review, 100(5):2510-31.

Gourinchas, P.-O. and Rey, H. (2014). External Adjustment, Global Imbalances, Valuation Effects. Handbook of International Economics, 4:585-645.

Gu, B., Wang, J., and Wu, J. (2014). Business Cycles in an Estimated DSGE Model of China. China Economic Journal, 7(3):361-381.

Havranek, T., Horvath, R., Irsova, Z., and Rusnak, M. (2015). Cross-country heterogeneity in intertemporal substitution. Journal of International Economics, 96(1):100-118. 
Havranek, T., Rusnak, M., and Sokolova, A. (2017). Habit formation in consumption: A meta-analysis. European Economic Review, 95:142-167.

Huynh, P., Nguyen, T., Duong, T., and Pham, D. (2017). Leaning against the Wind Policies on Vietnam's Economy with DSGE Model. Economies, ISSN 2227-7099, MDPI, Basel, 5(1):1-18.

Ireland, P. N. (2004). Technology Shocks in the New Keynesian Model. Review of Economics and Statistics, 86(4):923-936.

Ireland, P. N. (2011). A New Keynesian Perspective on the Great Recession. Journal of Money, Credit and Banking, 43(01):32-54.

Justiniano, A. and Preston, B. (2010a). Can structural small open-economy models account for the influence of foreign disturbances? Journal of International Economics, 81(1):61-74.

Justiniano, A. and Preston, B. (2010b). Monetary policy and uncertainty in an empirical small open-economy model. Journal of Applied Econometrics, 25 (1):93-128.

Jääskelä, J. P. and Nimark, K. (2011). A Medium-Scale New Keynesian Open Economy Model of Australia. Economic Record, 87(276):11-36.

Kehoe, T. J. and Ruhl, K. J. (2009). Sudden stops, sectoral reallocations, and the Real Exchange Rate. Journal of Development Economics, 89:235-249.

Khieu, H. V. (2014). The Role of Monetary Policy in the New Keynesian Model: Evidence from Vietnam. International Economic Journal, 29(1):138-160.

Kolasa, M. and Rubaszek, M. (2018). Does the foreign sector help forecast domestic variables in DSGE models? International Journal of Forecasting, 34(4):809-821.

Kose, M. A. (2002). Explaining Business Cycles in Small Open Economies 'How Much Do World Prices Matter? Journal of International Economics, 56:299-327.

Le, H. (2014). Dynamics of Business Cycles in Vietnam: A comparison with Indonesia and Philippines. Munich Personal RePEc Archive.

Liu, L. and Zhang, W. (2010). A New Keynesian model for analysing monetary policy in Mainland China. Journal of Asian Economics, 21:540-551.

Medina, J. P. and Soto, C. (2007). The Chilean Business Cycles through the Lens of a Stochastic General Equilibrium Model. Working Papers Central Bank of Chile, 457.

Mendoza, E. (1995). The Terms of Trade, the Real Exchange Rate, and Economic Fluctuations. International Economic Review, 36:101-137.

Mendoza, E. G. (2010). Sudden Stops, Financial Crises, and Leverage. American Economic Review, 100(5):1941-66. 
Mendoza, E. G. and Yue, V. Z. (2012). A General Equilibrium Model of Sovereign Default and Business Cycles. The Quarterly Journal of Economics, 127(2):889-946.

Monacelli, T. (2005). Monetary policy in a low pass-through environment. Journal of Money, Credit and Banking, 37:1047-1066.

Negro, M. D., Eusepi, S., Giannoni, M., Sbordone, A., Tambalotti, A., Cocci, M., Hasegawa, R., and Linder, M. H. (2013). The FRBNY DSGE Model. Federal Reserve Bank of New York Staff Reports, No.647.

Negro, M. D. and Schorfheide, F. (2008). Forming priors for DSGE models (and how it affects the assessment of nominal rigidities). Journal of Monetary Economics, 55(7):11911208.

Neumeyer, P. A. and Perri, F. (2005). Business cycles in emerging economies: the role of interest rates. Journal of Monetary Economics, 52(2):345-380.

Nimark, K. P. (2009). A Structural Model of Australia as a Small Open Economy. The Australia Economic Review, 42(1):24-41.

Oviedo, P. M. and Yue, V. Z. (2009). World Interest Rate and Business Cycles in Small Open Economies. Working Paper Iowa State University.

Palma, A. A. and Portugal, M. S. (2014). Preferences of the Central Bank of Brazil under the inflation targeting regime: Estimation using a DSGE model for a small open economy. Journal of Policy Modeling, 36(5):824-839.

Pham, B. T. (2018). Public investment and Vietnam business cycles: a DSGE approach. Unpublished.

Ramayandi, A. (2011). Impact of International Financial Shocks on Small Open Economies:The Case of Four ASEAN Countries. ADB Economics Working Paper Series No. 253.

Rees, D. M., Smith, P., and Hall, J. (2016). A Multi-sector Model of the Australian Economy. Economic Record, 92(298):374-408.

Sahminan, Utama, G., Rakman, R. N., and Idham (2017). A Dynamic Stochastic General Equilibrium (DSGE) Model to Assess the Impact of Structural Reforms on the Indonesian Economy. Bulletin of Monetary Economics and Banking, 20(2):149-180.

Sala, H., Pham, B. T., and Silva, J. I. (2019). Growth and real business cycles in Vietnam and the ASEAN-5. Does the trend shock matter? Economic Systems, forthcoming.

Saxegaard, M., Anand, R., and Peiris, S. J. (2010). An Estimated Model with Macrofinancial Linkages for India. IMF Working Paper No. 10/21. 
Schmitt-Grohé, S. and Uribe, M. (2003). Closing small open economy models. Journal of International Economics, 61(1):163-185.

Schmitt-Grohé, S. and Uribe, M. (2018). How important are Terms-Of-Trade shocks? International Economic Review, 59(1):85-111.

Silveira, M. A. C. (2008). Using a Bayesian approach to estimate and compare new Keynesian DSGE models for the Brazilian economy: the role for endogenous persistence. Revista Brasileira de Economia, 62(3):333-357.

Smets, F. and Wouters, R. (2003). An estimated Dynamic Stochastic General Equilibrium Model of the Euro Area. Journal of the European Economic Association, 1(3):1123-1175.

Smets, F. and Wouters, R. (2007). Shocks and frictions in US business cycles: A Bayesian DSGE approach. American Economic Review, 97 (3):586-606.

Steinbach, M., Mathuloe†, P., and Smit, B. (2009). An open economy NEW KEYNESIAN DSGE model of the South African economy. South African Journal of Economics, $77(2): 207-227$.

Taylor, J. B. (2000). Using Monetary Policy Rules in Emerging Market Economies. the 75th Anniversary Conference, "Stabilization and Monetary Policy: The International Experience," November 14-15, 2000, at the Bank of Mexico.

Uribe, M. and Yue, V. Z. (2006). Country spreads and emerging countries: Who Drives Whom? Journal of International Economics, 69(1):6-36.

\section{Appendices}

\section{A Data sources}

In the empirical analysis we use 10 following quarterly macroeconomic time series 
Table 3: Data sources, 1998Q4-2017Q1

\begin{tabular}{lll}
\hline & \multicolumn{1}{c}{ Variables } & Data sources \\
\hline$\tilde{y}_{t}$ & CPI-deflated GDP $(\log )$ & The GSO \\
\hline$\tilde{p}_{t}$ & CPI index (log) & The IMF-IFS Database \\
\hline$\tilde{i}_{t}$ & Central bank policy interest rate & The IMF-IFS Database \\
\hline$\tilde{e}_{t}$ & Nominal exchange rate against the USD $(\log )$ & The IMF-IFS Database \\
\hline$s_{t}$ & $\begin{array}{l}\text { The 45-individual commodidy } \\
\text { net export price index (log) }\end{array}$ & The IMF Database \\
\hline$\tilde{q}_{t}$ & CPI-based real exchange rate $(\log )$ & Calculated with $\tilde{p}_{t}$ and $\tilde{e}_{t}$ \\
\hline$\tilde{y}_{t}^{*}$ & Foreign GDP (US) per capita & The Fed St. Louis \\
& at constant prices (log) & \\
\hline$\tilde{p}_{t}^{*}$ & Foreign CPI index (US) (log) & The Fed St. Louis \\
\hline$\tilde{i}_{t}^{*}$ & The US interest rate & The Fed St. Louis \\
\hline \hline
\end{tabular}

Note:The GSO stands for the General Statistic Office of Vietnam.

Note that in this paper we will not detrend or demean the data prior to estimation. Instead, we will do it within the estimation procedure by including intercepts in the measurement equations wherever applicable.

We use a number of following online database to collect data in table 3 :

1. The $\boldsymbol{C P I}$ : https://data.imf .org/regular.aspx?key=61545861

2. The central bank policy interest rate: https://data.imf.org/regular. aspx?key=61545867

3. The Nominal exchange rate: https://data.imf.org/regular.aspx?key= 61545850

4. Commodity term of trade :

https://data.imf .org/?sk=2CDDCCB8-0B59-43E9-B6A0-59210D5605D2

5. Foreign real GDP per cap :

https://fred.stlouisfed.org/series/A939RX0Q048SBEA

6. Foreign CPI index : https://fred.stlouisfed.org/series/CPALTT01USQ661S

7. The Fed interest rate: https://data.imf .org/regular. aspx?key=61545867

Other annual macroeconomic indicators are used in this paper such as the broad money growth, etc. These indicators are collected from following online databases:

1. The annual broad money growth: https://datacatalog.worldbank.org/ dataset/world-development-indicators

2. The annual growth rate of GDP: https://data.worldbank.org/indicator/ NY.GDP.MKTP.KD.ZG?locations=VN

3. The annual openness: https://data.worldbank.org/indicator/ne.trd. gnfs.zs

4. The global price of Brent Crude: https://fred.stlouisfed.org/series/ POILBREUSDQ

5. The annual CPI inflation in Vietnam : https://data.worldbank.org/ indicator/FP.CPI. TOTL.ZG?locations $=\mathrm{VN}$ 
6. The annual constant GDP-per-cap growth rate of Vietnam : https: //fred.stlouisfed.org/series/NYGDPPCAPKDVNM

\section{B The measurement equation system}

$$
\begin{array}{r}
y_{t}^{o b s}-y_{t-1}^{o b s}=\mu_{y}+y_{t}-y_{t-1} \\
p_{t}^{o b s}-p_{t-1}^{o b s}=\mu_{p}+p_{t}-p_{t-1} \\
4 * i_{t}^{o b s}=\mu_{i}+4 * i_{t} \\
q_{t}^{o b s}-q_{t-1}^{o b s}=\mu_{q}+q_{t}-q_{t-1} \\
s_{t}^{o b s}-s_{t-1}^{o b s}=\mu_{s}+s_{t}-s_{t-1} \\
y_{t}^{o b s, f}-y_{t-1}^{o b s, f}=\mu_{y *}+y_{t}^{*}-y_{t-1}^{*} \\
p_{t}^{o b s, f}-p_{t-1}^{o b s, f}=\mu_{p *}+p_{t}^{*}-p_{t-1}^{*} \\
4 * i_{t}^{o b s, f}=\mu_{i^{*}}+4 * i_{t-1}^{*}
\end{array}
$$

It is worth noting that in the original version of the state-space model, the measurement equation has both intercept and error terms. However, in this paper, the above measure equation has only intercept. There are two explanations for this specification. The first reason is to reduce the complexity of estimation. Moreover, in the underlying theoretical model, the number of shocks is higher than the number of observed variables. Thus, the problem of the singularity does not exist, and the inclusion of non-structural shocks in the measurement equation would not be necessary. The second reason is that the strategy of this specification is often used in the literature, such as the well-known studies of Smets and Wouters (2007), Negro et al. (2013) and others Choi and Hur (2015), Kolasa and Rubaszek (2018). 


\section{Prior vs Posterior densities}
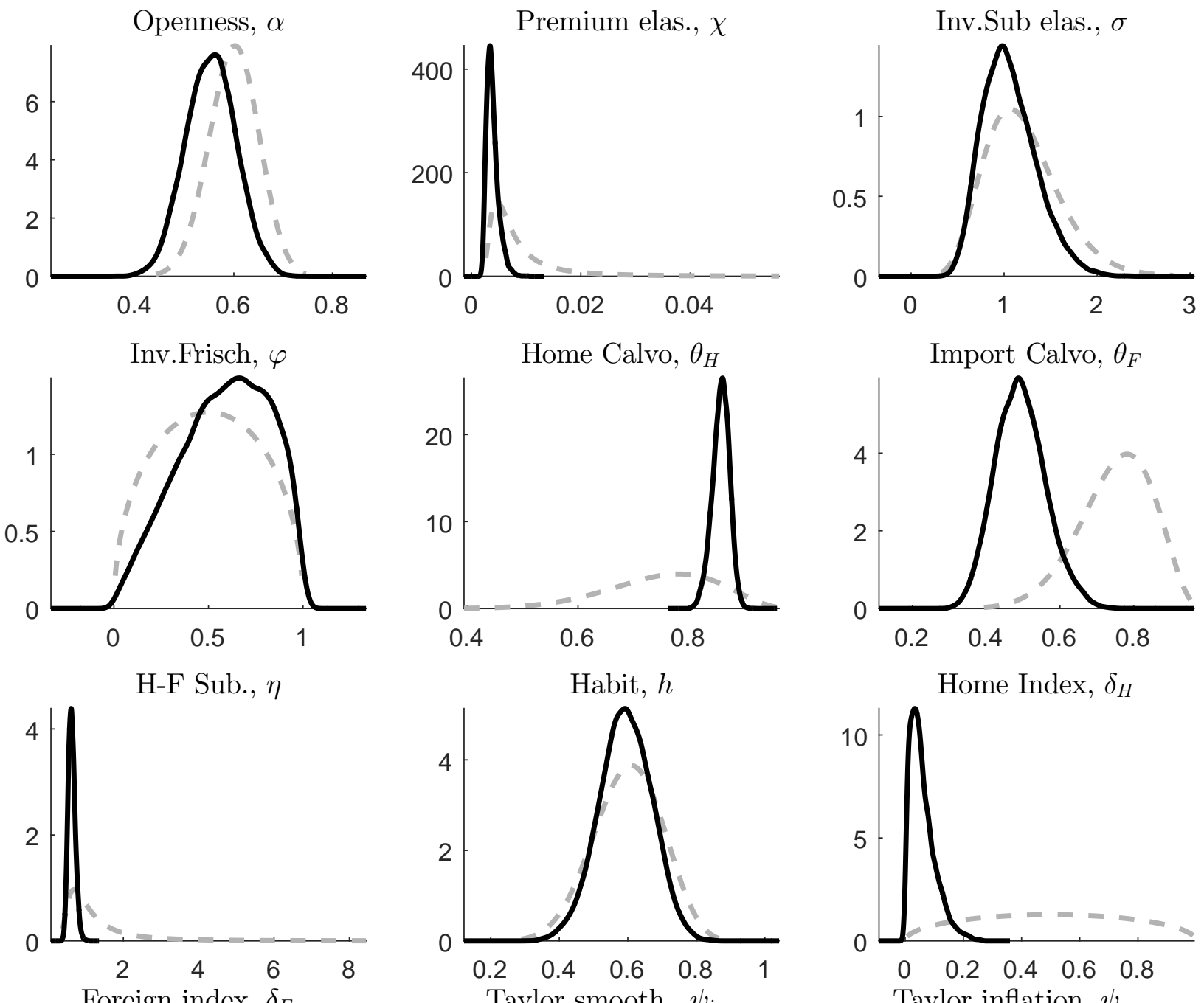

Foreign index, $\delta_{F}$
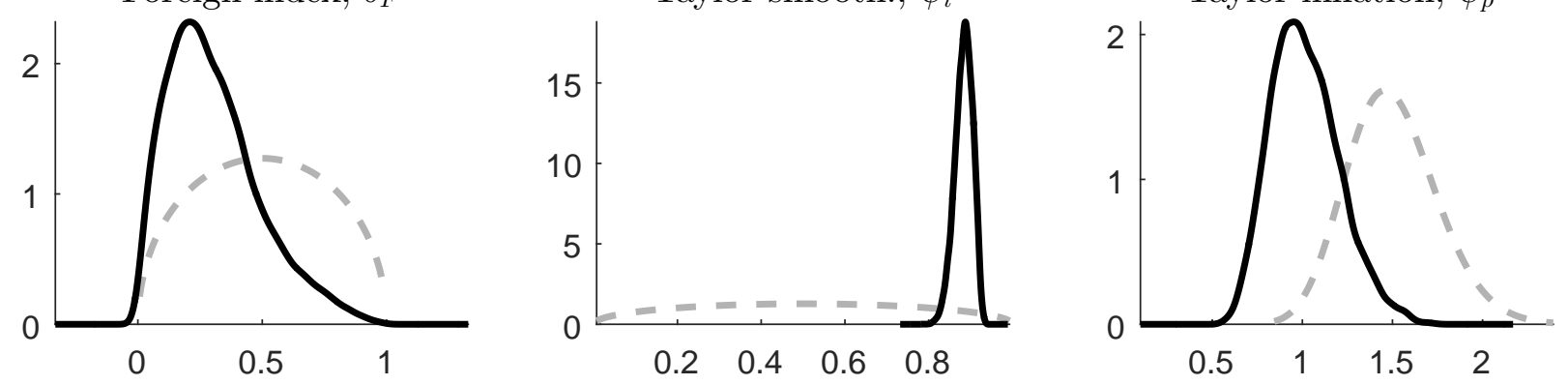

Taylor output, $\psi_{y}$
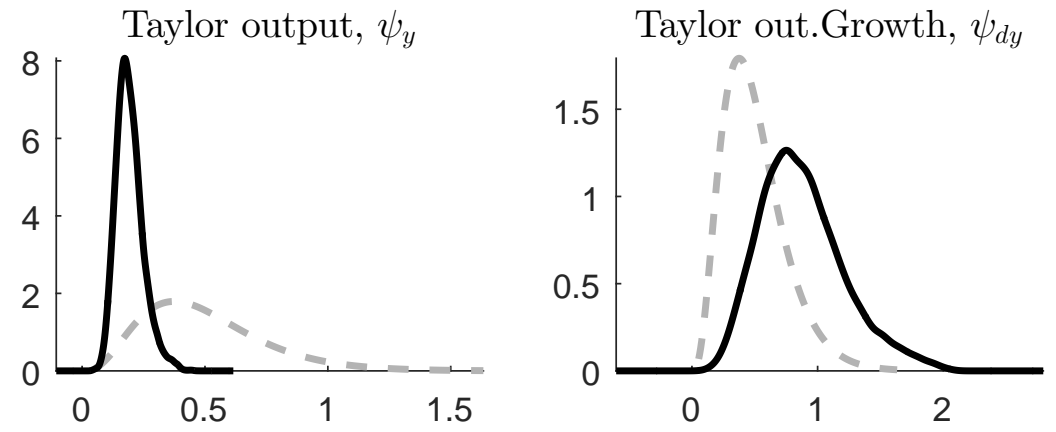

Taylor ex.Rate, $\psi_{d e}$

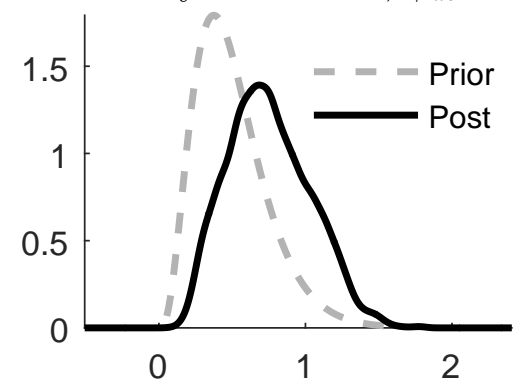

Figure 15: Prior and posterior densities 
Tech. Persistent, $\rho_{z}$

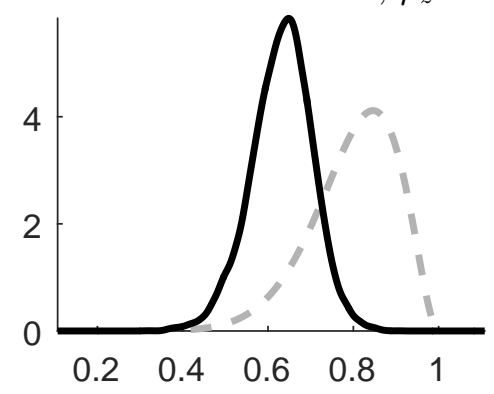

Risk Pre.Persistent, $\rho_{r p}$

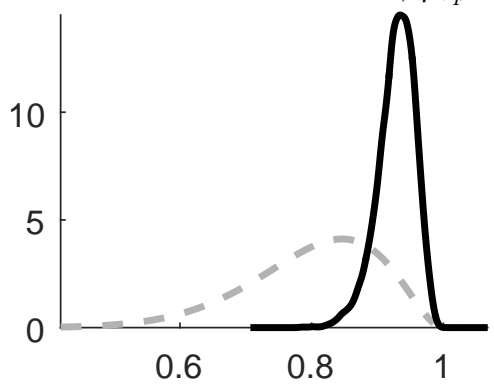

Sd.Cost-push, $\sigma_{c p}$
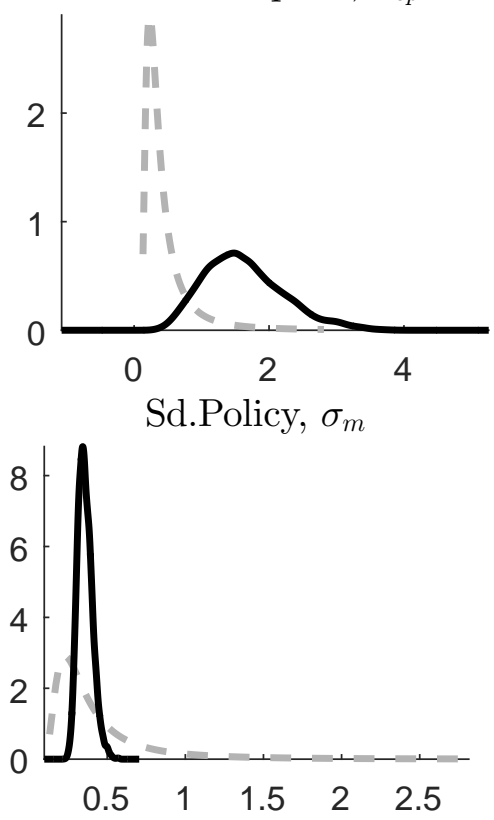

Per.For.Cost-push, $\rho_{p *}$

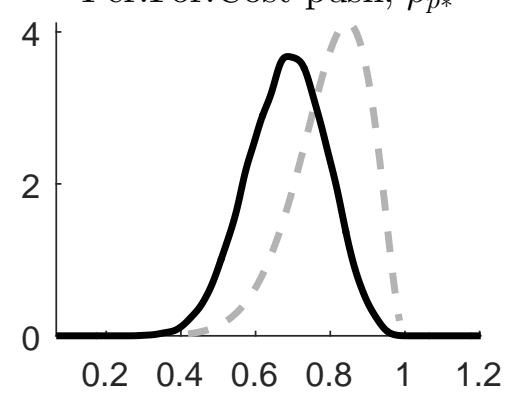

Pref.Persistent, $\rho_{g}$

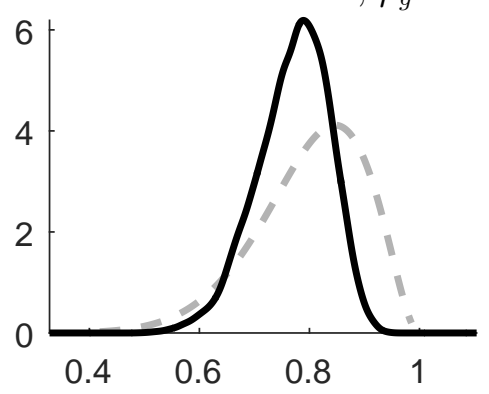

Sd.Technology, $\sigma_{z}$

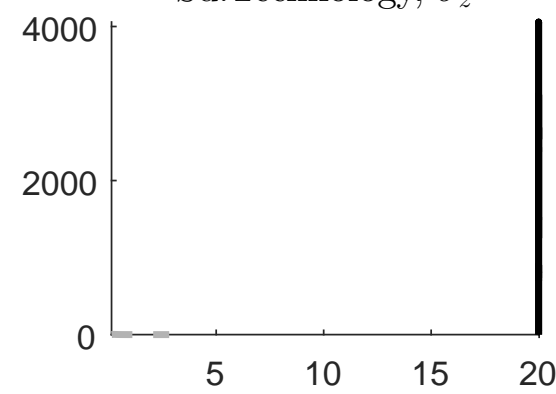

Sd.Risk premium, $\sigma_{r p}$

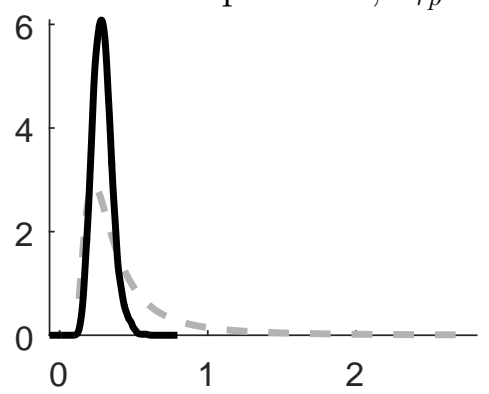

For.Steady-state growth, $z^{*}$

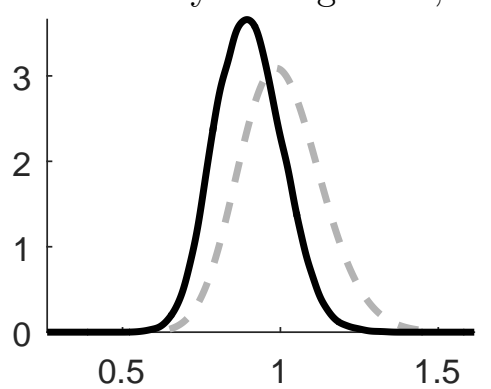

Per.For.Preference, $\rho_{a *}$

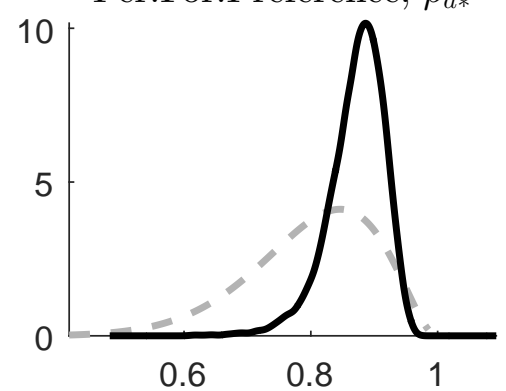

Cost-push Perisistent, $\rho_{c p}$

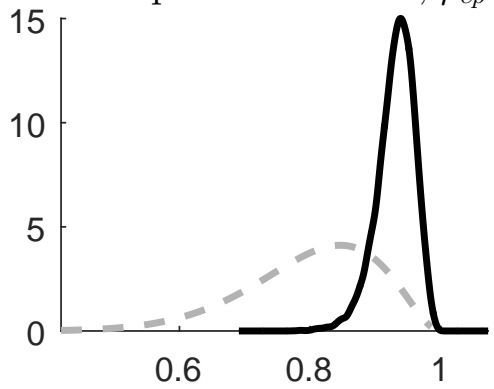

Sd.Preference, $\sigma_{g}$

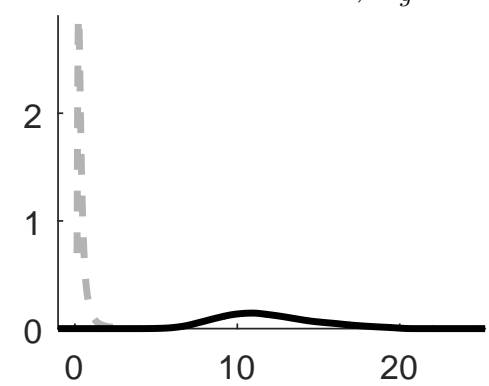

Sd.Term of Trade, $\sigma_{t o t}$

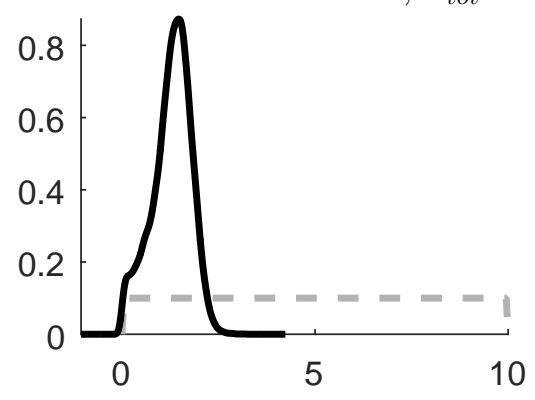

Foreign habit, $h^{*}$

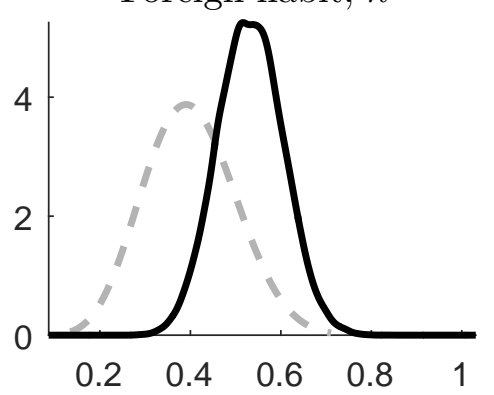

For.Price index., $\alpha^{*}$

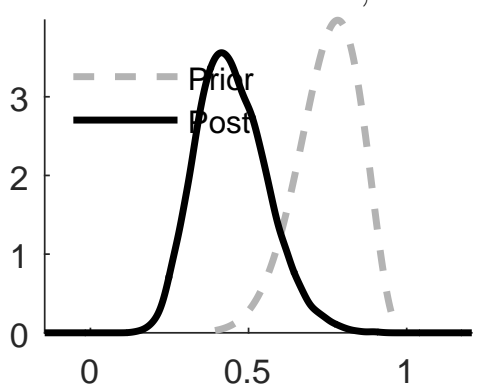

Figure 16: Prior and posterior densities 
For.Taylor, smoothing $\psi_{i *}$

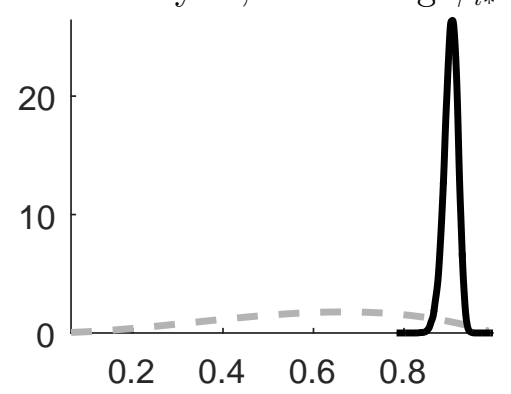

For.Taylor, out.Growth $\psi_{\Delta y *}$

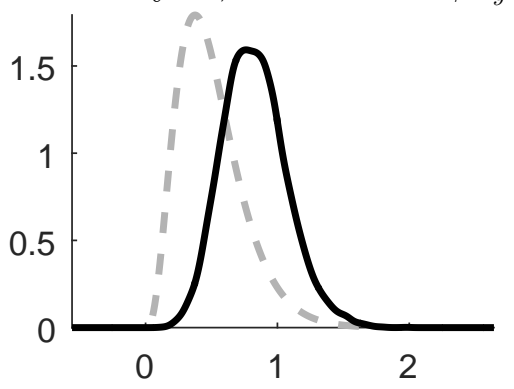

Sd.For.Cost-push, $\sigma_{c p *}$
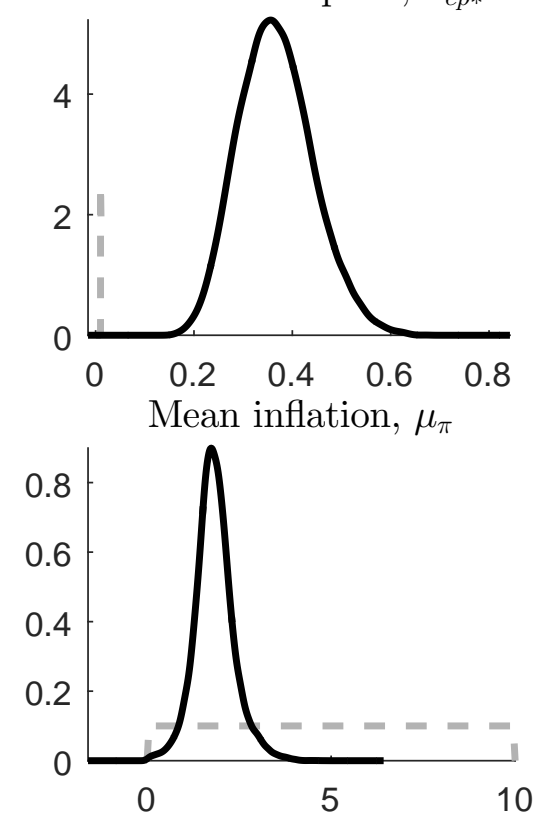

Mean interest rate, $\mu_{i}$

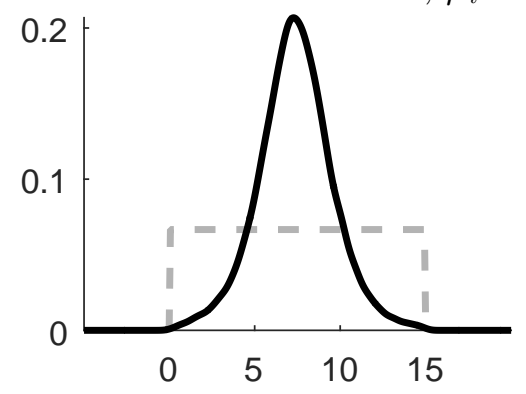

For.Taylor, price $\psi_{\pi *}$

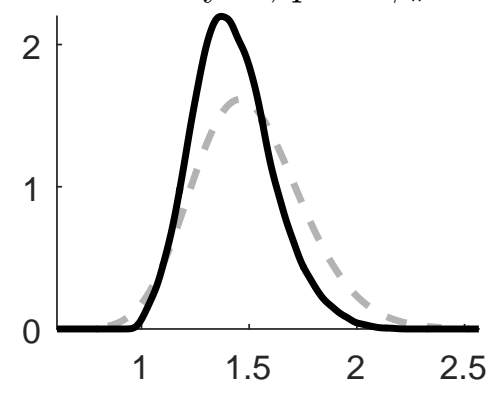

Sd.For.Interst, $\sigma_{i *}$

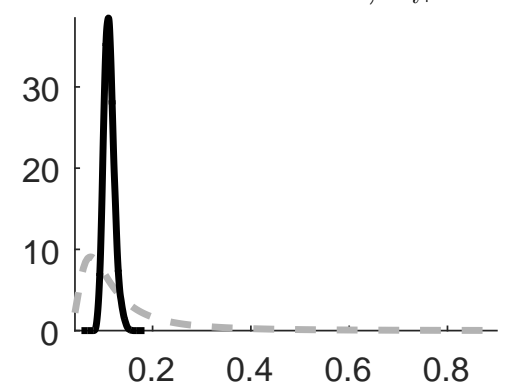

Sd.For.Technology, $\sigma_{z *}$
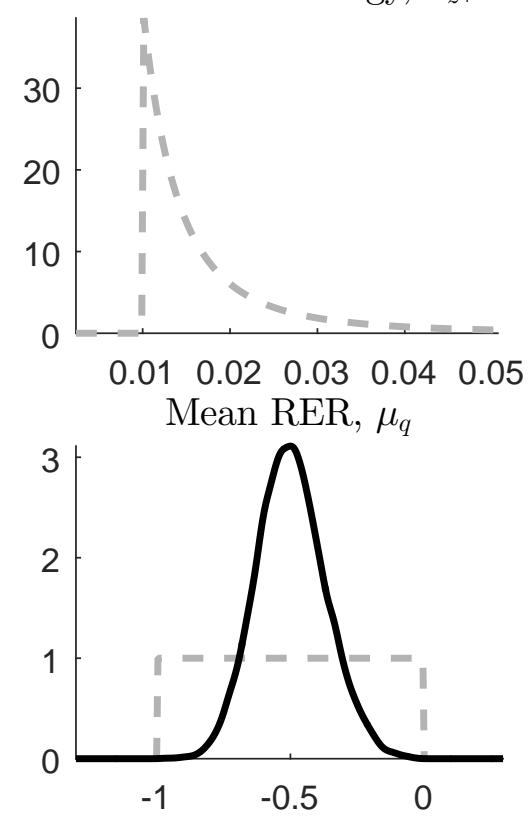

Mean for.Inflation, $\mu_{\pi *}$

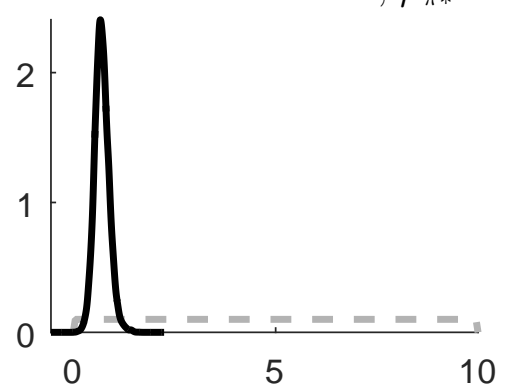

For.Taylor, output $\psi_{y *}$

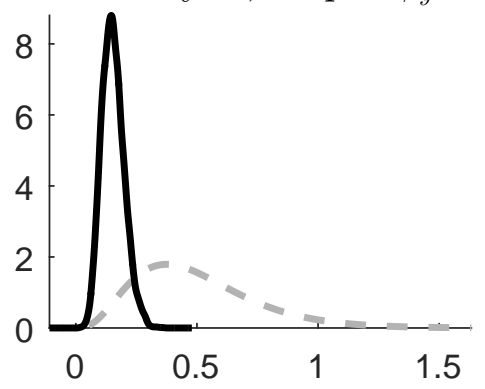

Sd.Foreign preference, $\sigma_{a *}$

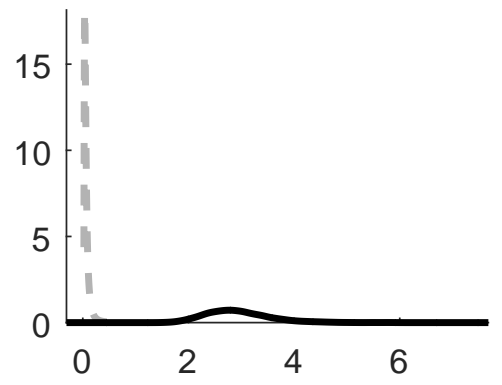

Mean output, $\mu_{y}$
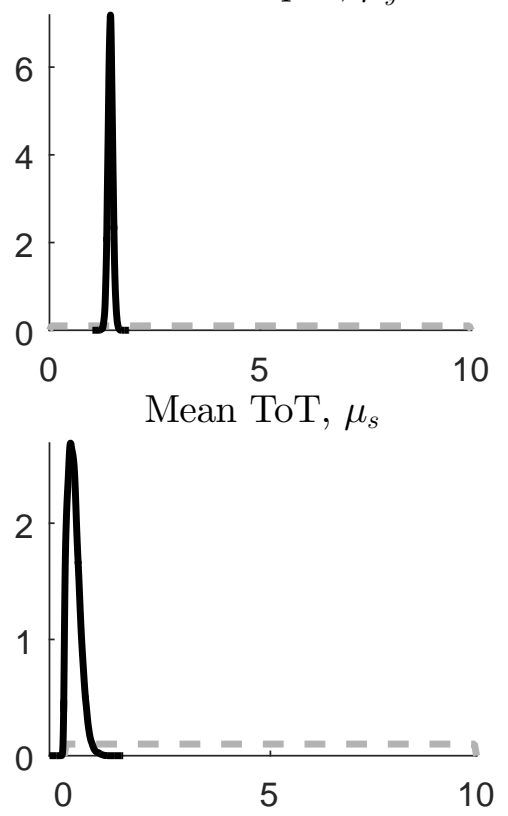

Mean for.Output, $\mu_{y *}$

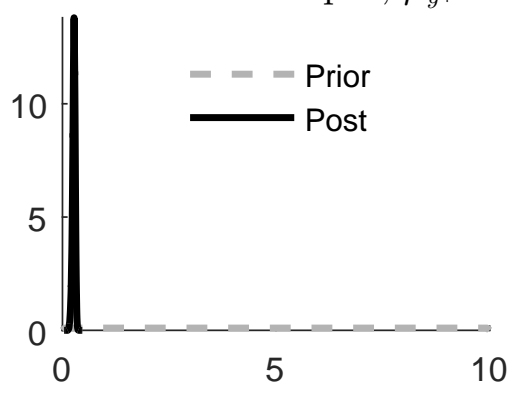

Figure 17: Prior and posterior densities 


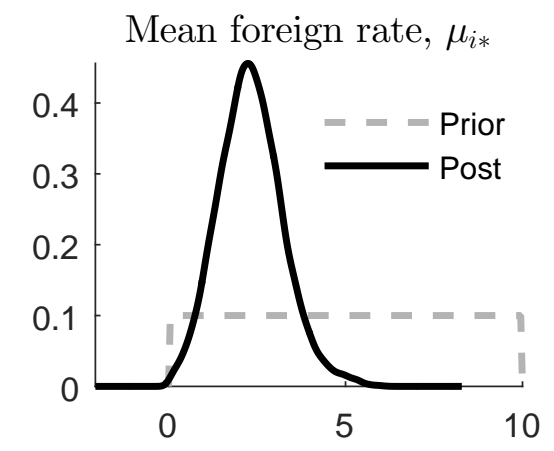

Figure 18: Prior and posterior densities

Figure 19: The smoothed shocks in Vietnam and foreign economy, 1999Q1-2017Q1
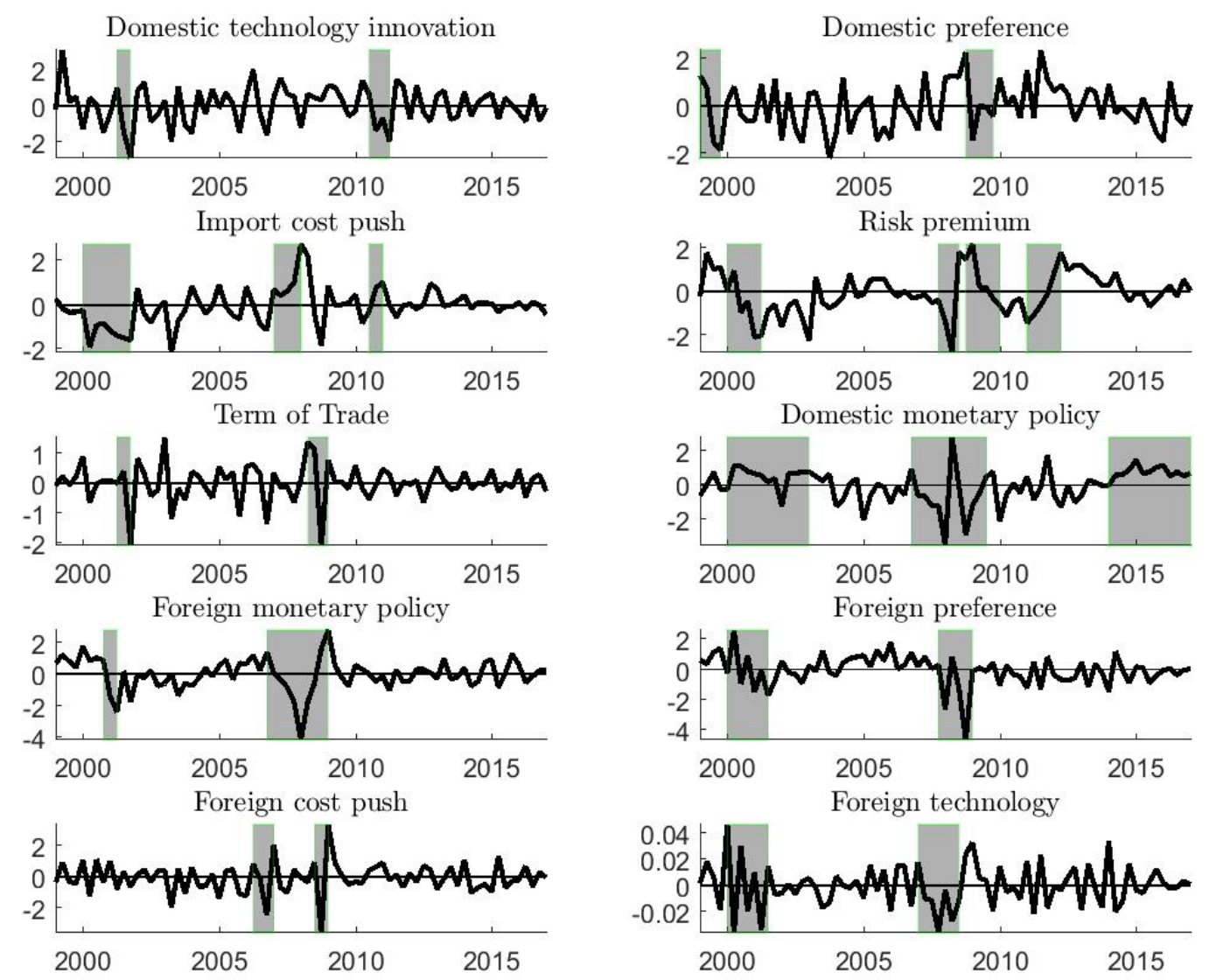